Linköping Studies in Science and Technology

Dissertation No. 2143

\title{
3D-printing for Aerospace:
}

\section{Fatigue Behaviour of Additive Manufactured Titanium}

\section{Magnus Kahlin}

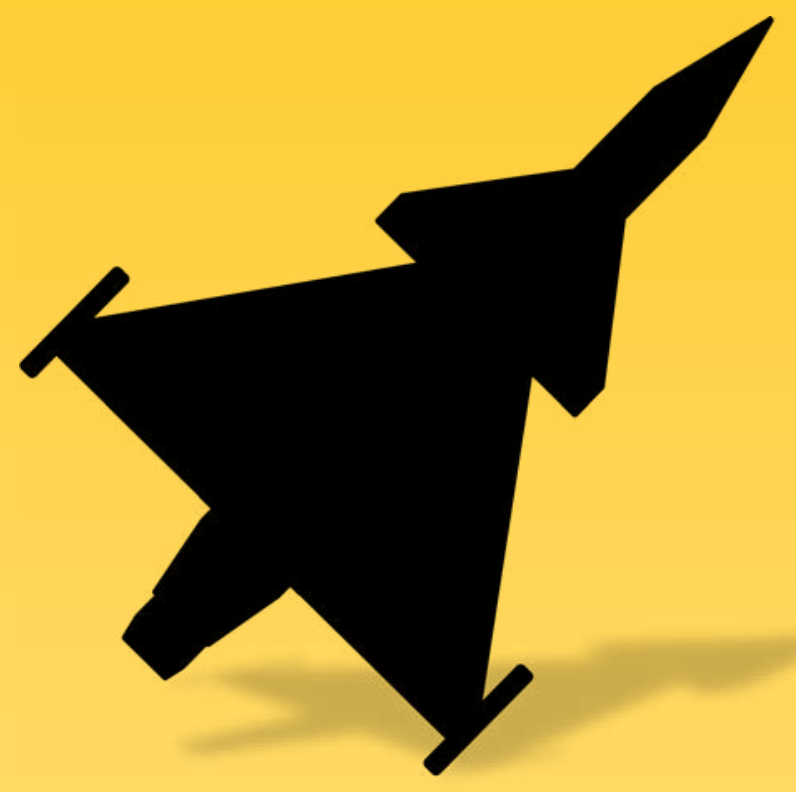



Linköping Studies in Science and Technology. Dissertations No. 2143

\title{
3D-printing for Aerospace:
}

Fatigue Behaviour of Additively Manufactured Titanium

\author{
Magnus Kahlin
}

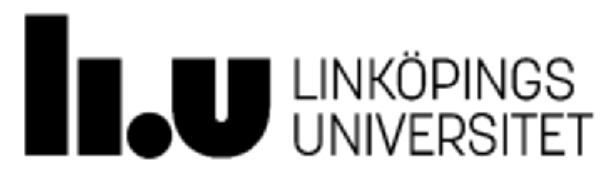

\author{
Division of Engineering Materials \\ Department of Management and Engineering (IEI) \\ Faculty of Science and Engineering \\ Linköping University, SE-581 83 Linköping, Sweden
}

Linköping 2021 
3D-printing for Aerospace: Fatigue Behaviour of Additively Manufactured Titanium

CCMagnus Kahlin, 2021

This work is licensed under a Creative Commons Attribution Non-Commercial 4.0 International License.

https://creativecommons.org/licenses/by-nc/4.0/

Printed in Sweden by LiU-tryck, 2021

ISSN: 0345-7524

ISBN: 978-91-7929-647-6 
Additive manufacturing, so-called $3 D$ printing, already affects how we produce critical components in our systems today. The introduction of this technology will explode in the coming years.

Håkan Buskhe 2018, President and CEO of Saab AB 2010-2019 


\section{Abstract}

Laser powder bed fusion (L-PBF) and electron beam powder bed fusion (E-PBF) are two of the most common additive manufacturing (AM) methods which both provide the engineer with a great freedom of design. This means that parts with light weight, multifunctional applications and improved performance could be achieved through innovative design solutions which have attracted a lot of interest from the aerospace industry.

This $\mathrm{PhD}$ project has focused on the following fatigue related areas for L-PBF and E-PBF Ti6Al4V material which all need to be addressed before AM can be fully introduced to critical aerospace applications: effect of geometry, roughness and loading on fatigue life, improved fatigue life through post processing, fatigue crack growth behaviour and fatigue prediction methods.

The results show that the rough as-built surface is the single most severe factor for fatigue but that the fatigue strength of at least L-PBF material can be improved to levels similar to conventionally manufactured material using surface post processing. Furthermore, the results verify that a cumulative damage approach gives good accuracy in predicting fatigue life for variable amplitude loading and that fatigue crack growth rates using material data from standard specimens can be used for damage tolerance analysis independent of part geometry and stress level.

The conclusion is therefore that the fatigue properties can be improved to acceptable levels and predicted using conventional methods. There are still some challenges to solve, however, especially within non-destructive testing before AM can be introduced to critical aerospace applications.

Keywords: additive manufacturing, fatigue, post processing, crack growth, Ti6Al4V, aerospace 


\section{Populärvetenskaplig sammanfattning}

Istället för att utgå från ett metallblock och ta bort material, som vid traditionell bearbetning, så bygger 3D-printing (additiv tillverkning) i metall upp en komponent genom att smälta metallpulver lager på lager. Detta gör att man kan tillverka komponenter med väldigt komplicerade geometrier. Genom att t.ex. ta bort allt "onödigt" material kan man på detta sätt få en väldigt lätt komponent, vilket i flygindustrin betyder minskad bränsleåtgång och minskade utsläpp. Man kan även designa in tunna kylkanaler inuti en apparat med hjälp av 3D-printing vilket ofta innebär att man kan öka effekten, då kylningen ofta är den begränsande faktorn. Effektivare apparater i ett flygplan kan i sin tur antingen minska bränsleförbrukningen eller ge bättre prestanda vilket är eftertraktat i både militära och civila tillämpningar. Även fast 3D-printade metallkomponenter redan nu finns i vissa flygplan så är det några utmatningar kvar att lösa innan hela potentialen hos 3D-printing kan utnyttjas och 3D-printade material kan införas i kritiska eller högt belastade komponenter. Från ett materialperspektiv så är det ofta utmattningshållfastheten som är den begränsande egenskapen då denna kan vara upp till $75 \%$ lägre för ett 3D-printat material jämfört mot samma material tillverkat med traditionella metoder. Denna försämring är främst kopplad till den grova ytan som man får vid 3D-printing. I denna yta kan en spricka lätt uppstå och sedan växa inåt i materialet. Forskningen som presenteras i denna avhandling visar dock att man kan få lika bra utmattningshållfasthet med 3D-printat titan, som vid traditionell tillverkning, genom efterbehandling av ytan, tex med trumling eller kulpening. Dessutom visar denna avhandling hur utmattningshållfastheten påverkas av att man kombinerar den grova ytan med geometriska anvisningar, t.ex. radier, där sprickor oftast uppstår. Befintliga beräkningsmetoder har även visat sig fungerarar utmärkt för att förutsäga hur många timmar som en komponent kan användas innan den börjar spricka samt hur fort denna spricka sedan växer. Att samma beräkningsmetoder kan användas för 3D-printat material som för traditionellt tillverkade material underlättar införandet och minskar osäkerheten när 3D-printade artiklar förs in på kritiska eller högt belastade flygplanskomponenter. De resultat som presenteras i denna avhandling har redan använts för flygplanskomponenter som nu är uppe och flyger men fortsatt forskning krävs för att man skall få ut den fulla potentialen av 3D-printing för flygande farkoster.

Nyckelord: 3D-printing, flyg, utmattning, titan 


\section{Acknowledgement}

There is only my name on the cover of this thesis but all the content on the inside could not have been accomplished without the massive support from a lot of people.

I gratefully acknowledge the funding received from the Swedish Foundation for Strategic Research (SSF) and from Clean Sky 2 under the European Union's Horizon 2020 research and innovation programme from without this research project would not have been possible.

Moreover, I would like to express my sincere gratitude to my supervisors professor Johan Moverare at Linköping University and adjunct professor Hans Ansell at Saab Aeronautics for their continued support and encouragements. Your combined experiences on fatigue properties and your opinions during discussions have been invaluable during these years.

I am, furthermore, very thankful for the input from the steering committee of this project, professor Sten Johansson at Linköping University and Anders Bredberg, Bertil Franzén, Marcus Claseryd and Tomas Ireman at Saab Aeronautics. My special regards to all the co-authors of my publications, thank you for all your efforts to complete our studies and an extra thank you to Annie Kerwin for excellent proof reading. To all my colleagues at Saab and Linköping University, thank you for all discussions during coffee breaks. I especially would like to recognize Patrik Härnman, Rodger Romero Ramirez and Annethe Billenius for technical assistance in the material laboratory and Ingmari Hallkvist for always being helpful with anything. To my former Saab-colleague Niklas Eriksson, thank you for taking this AM journey with me, it took some time, but things are now finally starting to happen.

Last but not least, I would like to thank my family. First my parents for supporting me throughout my life. And finally, to my beloved wife Anna and children Clara and Oskar - without you my life would fall apart. I might not know where life will take me, but knowing you are with me has given me the strength to do anything.

Magnus Kahlin, Linköping 2021

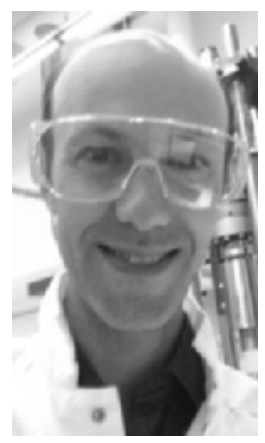





\section{List of Papers}

This thesis is based on the following papers, which are referred to in the thesis by their Roman numbers:

I. M. Kahlin, H. Ansell, J.J. Moverare, Fatigue behaviour of notched additive manufactured Ti6Al4V with as-built surfaces, International Journal of Fatigue, vol. 101, pp. 51-60, 2017, doi.org/10.1016/j.ijfatigue.2017.04.009

II. M. Kahlin, H. Ansell, J.J. Moverare, Fatigue behaviour of additive manufactured Ti6Al4V, with as-built surfaces, exposed to variable amplitude loading, International Journal of Fatigue, vol. 103, pp. 353-362, 2017, doi.org/10.1016/j.ijfatigue.2017.06.023

III. M. Kahlin, H. Ansell, D. Basu, A. Kerwin, L. Newton, B. Smith, J.J. Moverare, Improved fatigue strength of additively manufactured Ti6Al4V by surface post processing, International Journal of Fatigue, vol. 134, article 105497, 2020, doi.org/10.1016/j.ijfatigue.2020.105497

IV. M. Kahlin, H. Ansell, A. Kerwin, B. Smith, J. Moverare, Variable amplitude loading of additively manufactured Ti6Al4V subjected to surface post processes, International Journal of Fatigue, vol. 142, article 105945 2021, doi.org/10.1016/j.ijfatigue.2020.105945

V. M. Kahlin, H. Ansell, J. Moverare, Fatigue Crack Growth for Through and Part-through Cracks in Additively Manufactured Ti6A14V, submitted for publication 2021

Papers not included in this thesis:

VI. L. Pejryd, P. Karlsson, S. Hällgren, M. Kahlin, ”Non-destructive evaluation of internal defects in additive manufactured aluminium", Presented at WorldPM2016, Hamburg (Germany), 2016

VII. M. Segersäll, A. Kerwin, A. Hardaker, M. Kahlin, J. Moverare, Fatigue response dependence of thickness measurement methods 
for additively manufactured E-PBF Ti-6Al-4V, Fatigue \& Fracture of Engineering Materials \& Structures, vol. 44, pp. 1931-1943, 2021, doi.org/10.1111/ffe.13461

\section{Author's Contribution}

My contributions to the included papers were:

I. I performed all material investigations and was the main contributor of the manuscript writing.

II. I performed all material investigations and was the main contributor of the manuscript writing. Hans Ansell performed the fatigue life predictions with cumulative damage calculations.

III. I performed all microscopy investigations and the majority of the mechanical testing and was the main contributor of the manuscript writing. Dr. Johan Moverare performed part of the mechanical testing. Dejan Basu and Annie Kerwin performed process parameter development. Dejan Basu and Dr. Lewis Newton performed surface roughness investigations. Jonas Holmberg performed residual stress measurements.

IV. I performed all microscopy investigations and the majority of the mechanical testing and was the main contributor of the manuscript writing. Dr. Johan Moverare performed part of the mechanical testing. Hans Ansell performed the fatigue life predictions with cumulative damage calculations. Dejan Basu and Annie Kerwin performed process parameter development. Dejan Basu and Dr. Lewis Newton performed the surface roughness investigations.

V. I performed all material investigations and was the main contributor of the manuscript writing. Hans Ansell performed the crack propagation modelling. 


\section{Contents}

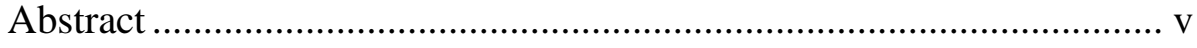

Populärvetenskaplig sammanfattning ............................................ vii

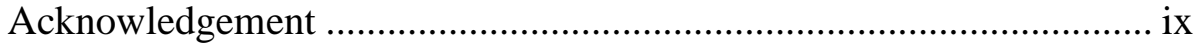

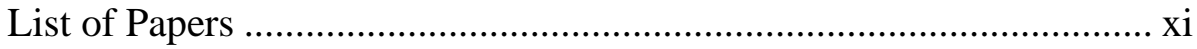

Author's Contribution ................................................................ xii

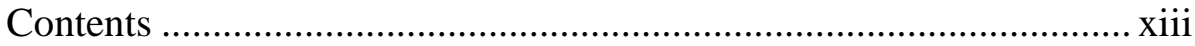

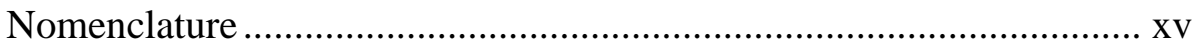

Part I: Background, Methods and Results .........................1 1

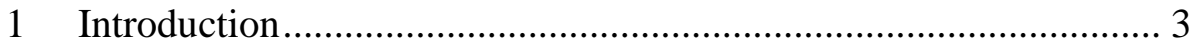

1.1 Challenges for a More Sustainable Aviation .............................. 3

1.2 Introduction to the Research Project............................................ 3

1.3 Aim of this Project ................................................................... 4

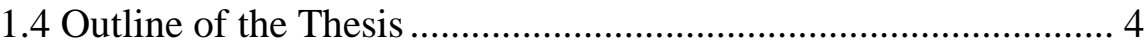

2 Additive Manufacturing ............................................................... 5

2.1 Powder Bed Fusion Processes..................................................... 6

2.1.1 E-PBF Compared to L-PBF Process ............................... 7

2.2 Why Should AM be Used ....................................................... 8

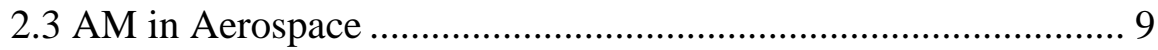

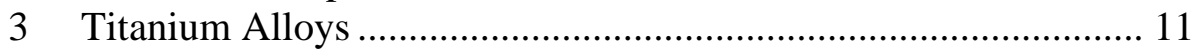

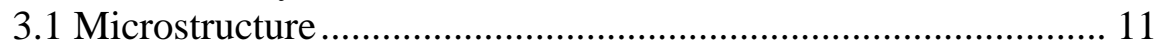

3.1.1. Conventional Produced Ti6Al4V ....................................12

3.1.2 E-PBF Produced Ti6Al4V ............................................13

3.1.3 L-PBF Produced Ti6Al4V ................................................. 14

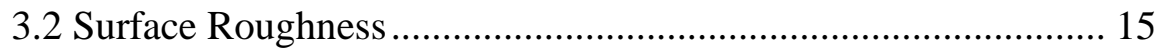

3.3 Internal Material Defects ............................................ 16

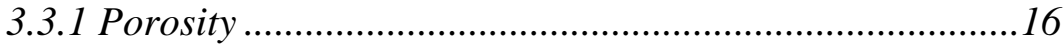

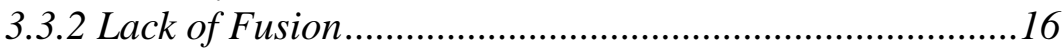

4 Materials, Experiments and Modelling ......................................... 19

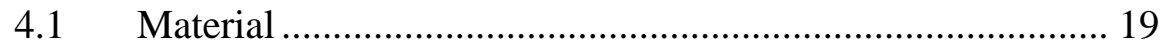

4.2 Post Processing ............................................................ 20

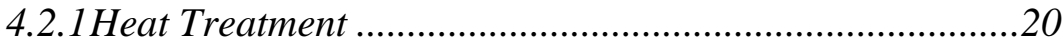

4.2.2Surface Post Processing..................................................21

$4.3 \quad$ Tensile Testing .................................................................... 22

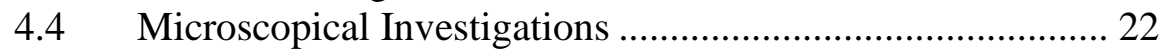

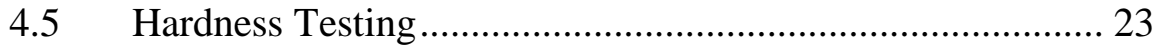

4.6 Surface Roughness Investigations .................................... 23

4.7 Surface Residual Stress Investigations ................................. 23 


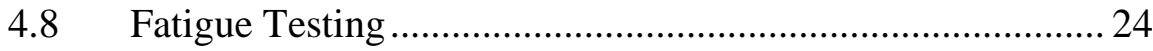

4.8.1 Constant Amplitude Loading........................................... 24

4.8.2 Variable Amplitude Loading .......................................... 24

4.9 Fatigue Life Prediction Models ......................................... 25

4.10 Fatigue Crack Growth Testing ........................................... 27

4.11 Fatigue Crack Growth Prediction Models............................ 29

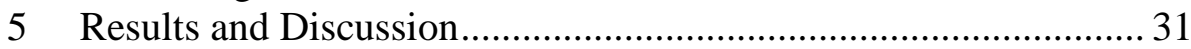

5.1 Effect of Surface Roughness and Residual Stress....................... 32

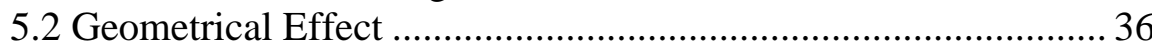

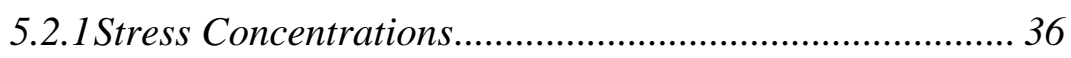

5.2.2 FCG with Through or Part-through Cracks ................... 39

5.3 Loading Effect................................................................................ 41

6 Summary of Appended Papers .................................................... 45

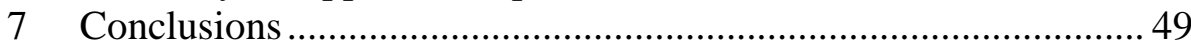

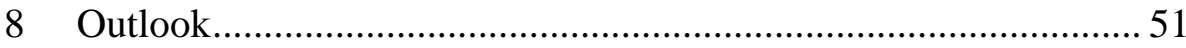

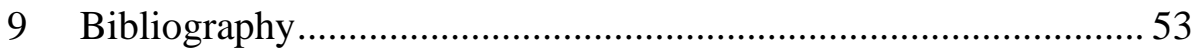

Part II: Papers Included ...................................................59 


\section{Nomenclature}

$\begin{array}{ll}\text { AB } & \text { as-built } \\ \text { AM } & \text { additive manufacturing } \\ \text { B.d. } & \text { build direction } \\ \text { CAD } & \text { computer aided design } \\ \text { CF } & \text { centrifugal finishing } \\ \text { COD } & \text { crack opening displacement } \\ \text { CT } & \text { compact-tension } \\ \text { DED } & \text { direct energy deposition } \\ \text { E-PBF } & \text { electron beam power bed fusion } \\ \text { FALSTAFF } & \text { fighter aircraft loading standard for fatigue } \\ \text { FCG } & \text { fatigue crack growth } \\ \text { FE } & \text { finite element } \\ \text { HIP } & \text { hot isostatic pressing } \\ \text { Lin } & \text { linishing } \\ \text { LOF } & \text { lack of fusion } \\ \text { LP } & \text { laser polishing } \\ \text { L-PBF } & \text { laser power bed fusion } \\ \text { LSP } & \text { laser shock peening } \\ \text { NDT } & \text { non-destructive testing } \\ \text { PBF } & \text { power bed fusion } \\ \text { SP } & \text { shot peening }\end{array}$




\section{Part I: Background, Methods and Results}




\section{Introduction}

\subsection{Challenges for a More Sustainable Aviation}

The need of reducing greenhouse gas emissions is a great challenge to the aerospace industry since aviation is to date responsible for about $2 \%$ of the worlds carbon dioxide $\left(\mathrm{CO}_{2}\right)$ emissions [1]. Additive manufacturing (AM) has been identified to have the potential of reducing the emissions with over $6 \%$ by, for example, light weight aerospace parts and increased performance of systems [2]. This potential is very much connected to the inherent design freedom of AM which can enable, for example, optimized light weight structures and systems with internal cooling channels. In addition to reduced emissions, an aircraft with lower weight and/or higher performance has also an increased payload, i.e. amount of weight that could be carried, and extended flight range which is beneficial for both civilian and military aircraft. There are, however, technical challenges that need to be solved before AM can be fully utilized in aerospace applications. These include challenges with productivity, repeatability, nondestructive testing (NDT), residual stress, surface roughness and low fatigue strength.

\subsection{Introduction to the Research Project}

This $\mathrm{PhD}$ project has been part of and received funding from two research project: Additive manufacturing: Performance in aerospace applications, through the Swedish Foundation for Strategic Research (SSF), project ID 14-0060, and Clean Sky 2 joint undertaking under the European Union's Horizon 2020 research and innovation programme under the work package A-3.3 Innovative Shapes \& Structure.

The $\mathrm{PhD}$ project has, furthermore, had synergies and collaboration with several other national and international research projects which are listed alphabetically below:

- ADDMAN - Innovative re-design and validation of complex airframe structural components formed by additive manufacturing for weight and cost reduction, Clean Sky 2, Horizon 2020.

- AMPeRE - Industrialisation of additive manufacturing through multi-purpose post-processing, Vinnova Metallic material. 
- CAM2 - Centre for additive manufacture - metal, Vinnova competence centre.

- INTDEMO - Aircraft, Vinnova Innovair

- OPTIPAM - Optimized production process for additive manufacturing, Vinnova Production2030.

Moreover, since the author is an industrial $\mathrm{PhD}$ student employed by Saab Aeronautics, the $\mathrm{PhD}$ research has, of course, been performed in close collaboration with Saab using an aerospace industrial perspective of the application of additive manufacturing. Saab has also been funding additional costs not covered by the SSF and Clean Sky 2 research projects.

\subsection{Aim of this Project}

The aim of this $\mathrm{PhD}$ project has been to investigate the fatigue and damage tolerance behaviour of additively manufactured Ti6Al4V to obtain sufficient confidence and knowledge for introduction to high performance aerospace applications. This includes increased understanding on how e.g. part geometry, loading conditions, surface roughness and post processing affect the material properties and how well existing predictions methods for fatigue life and crack growth propagations can predict the behaviour of additively manufactured Ti6Al4V material.

\subsection{Outline of the Thesis}

This thesis consists of two parts:

Part I: Background, methods and results, which includes several introductory chapters, a description of the methods used and the main results from the appended papers. Finally, conclusions and an outlook for possible future work are given.

Part II: Papers included, collects five papers that describes the research performed within the project.

This thesis builds upon the previous work of the licentiate thesis Fatigue Performance of Additive Manufactured Ti6Al4V in Aerospace Applications [3], which was presented in June 2017 and hence the text in chapter 3 in this thesis is taken nearly directly from [3]. 


\section{Additive Manufacturing}

Additive manufacturing (AM), also commonly referred to as 3D-printing, is a group of manufacturing methods that build up a part by adding new material layer-by-layer in contrast to subtractive manufacturing, e.g. milling, which removes material from a block to create a part. AM has therefore a much greater design freedom, than milling and casting, and parts can be designed with more complex geometries, as seen in Figure 1, which can give improved part performance or reduced costs [4][5]. Originating from prototyping using polymer material in the 1980s [6], AM is today used for serial production of metal parts [7][8][9]. However, AM is still an expensive manufacturing process and metal serial production has in general been limited to high-end-products, for example aerospace or gas turbine applications, or very customized products like medical implants [8][10]. Moreover, due to the high cost, AM has been mainly used for serial production of expensive and difficult-to-machine materials, as titanium or nickel based materials, for small to medium size production lots [5][11].

These "old trues" are, however, starting to change as production rates for new AM equipment increase and material interests are extended to include, for example steel and aluminium alloys for serial produced parts.

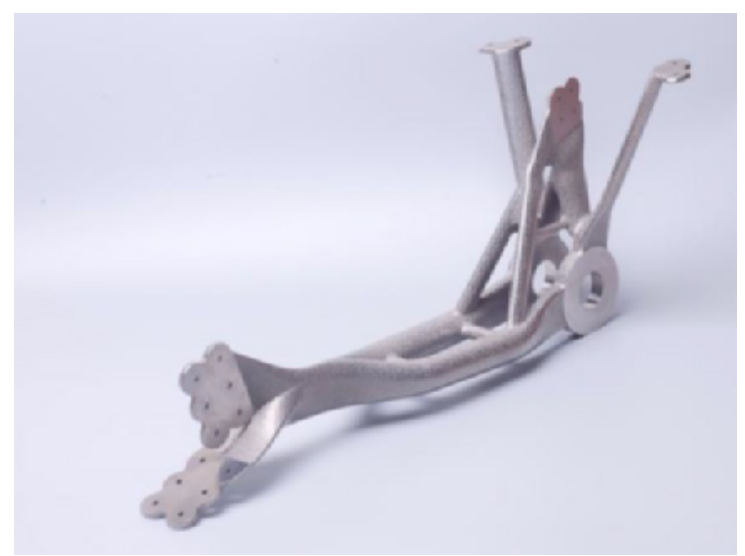

Figure 1. A Ti6A14V lift fitting for an aircraft cargo door designed for AM for demonstration purpose. Image courtesy of Rodger Romero Ramirez (Linköping University). 
There are several different AM techniques for manufacturing metal parts in which the two main groups are powder bed fusion (PBF) and direct energy deposition (DED) [5]. In the present research project, the focus has been on titanium alloy Ti6Al4V manufactured with PBF processes.

\subsection{Powder Bed Fusion Processes}

A PBF process is schematically illustrated in Figure 2, in which a computer model, of the part that is to be manufactured, is sliced into thin layers and then manufactured layer-by-layer. A thin layer of pre-alloyed metal powder is spread out onto a build plate [5]. The powder for the bottom slice of the part is melted using either a laser, laser powder bed fusion (L-PBF), or an electron beam, electron beam powder bed fusion (E-PBF), leaving all excess powder un-melted. The build platform is then lowered, a new layer of un-melted powder is spread out and the next slice of the part is melted. The procedure is repeated until the full geometry of the part has been manufactured. Support structure, which is a thin latticelike structure, is manufactured simultaneously as the part to keep the part from distortion during the build, transport heat away and to support large overhangs that cannot be supported by the surrounding un-melted powder as illustrated in Figure 2 [12].

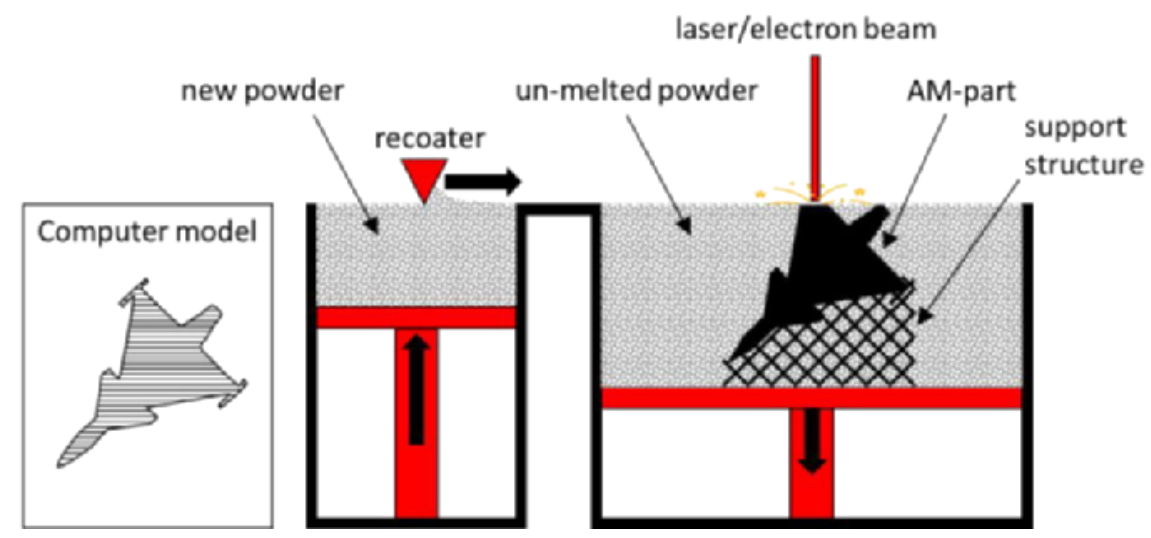

Figure 2. Powder bed fusion process schematically illustrated.

There are numerous process parameters controlling the PBF processes, for example layer thickness, scan speed, hatch distance, laser power, electron beam current and scan strategy [13]. Scan strategy can be for exam- 
ple scan rotation between layers, contour melting or hatch melting. Contour melting includes normally 2-3 overlapping "fine" runs [14][15] with the laser, or electron beam, around the outer contour of each slice to achieve a final geometry with good geometrical accuracy and low surface roughness [16]. Thereafter, hatch melting is used to "fill" the interior of each slice and producing the bulk material with a higher build rate (high power and high scan speed) [16]. The optimal parameters are different for different materials and adjustment of parameters can for example be needed to improve production rate or material properties [13][17].

Every time a new layer of powder is melted, several already solidified layers below are re-melted or heat affected. This gives AM material a very complex thermal history, as illustrated in Figure 3 for L-PBF, with quick cooling followed by re-melting, and re-heating [5].

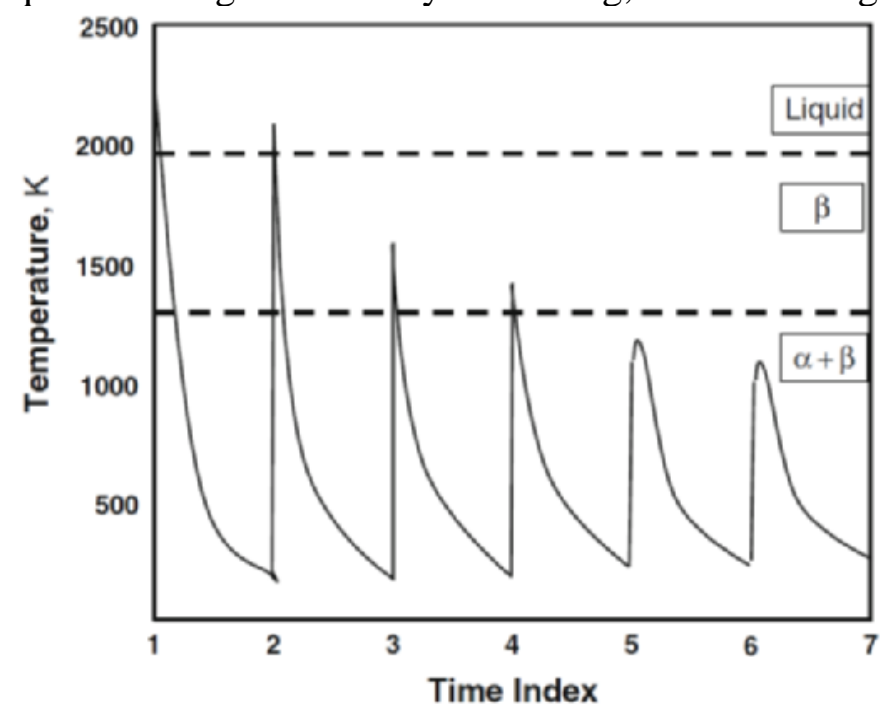

Figure 3. Schematic illustration of temperature exposure of a single layer Ti6Al4V during L-PBF. Reprinted by permission from Springer Nature, Frazier [5], 2014๑.

\subsubsection{E-PBF Compared to L-PBF Process}

There are some differences between E-PBF and L-PBF processes even though they use the same basic principles. The main differences are listed in Table 1 in which the most fundamental difference is the "cold" L-PBF process, in which already solidified layers only are exposed to high temperatures during the next few added layers, see Figure 3, in contrast to the 
"hot" E-PBF process in which the entire powder bed, both melted and unmelted powder, is kept at high temperature, about $700^{\circ} \mathrm{C}(973 \mathrm{~K})$ [9] for Ti6Al4V, during the entire build time. This results in major residual stresses in the L-PBF material which generally requires post stress relieving heat treatment in contrast to E-PBF material which is constantly annealed throughout the PBF process. Furthermore, E-PBF material has a considerably larger surface roughness compared to L-PBF which is mainly attributed to the larger layer thickness and larger particle size for the E-PBF process [18], see Table 1.

Table 1. L-PBF compared to E-PBF process for Ti6Al4V material.

\begin{tabular}{|l|l|l|}
\hline & L-PBF & E-PBF \\
\hline Environment & Argon gas*[19][20] & Vacuum [9] \\
\hline Heated powder bed & No** $^{* *}$ Yes $\left(\sim 700^{\circ}\right.$ C) [9] \\
\hline Powder size & $20-63 \mu \mathrm{m}[19][20]$ & $45-106 \mu \mathrm{m}[9]$ \\
\hline Layer thickness & $30-60 \mu \mathrm{m}[19][20]$ & $50-90 \mu \mathrm{m}[9][21]$ \\
\hline
\end{tabular}

* Argon is most common for titanium, but other inert gases can be used. $* *$ Some build plates have a minor heat capability $\sim 200^{\circ} \mathrm{C}[20]$

There are, furthermore, different manufacturing systems available for both E-PBF and L-PBF respectively which, even though similar, use different setups and process parameters that can give variations in material properties even if the same alloy is used [22].

\subsection{Why Should AM be Used}

The design freedom and the possibility to customize a single part or small batches without additional manufacturing costs are the key benefits of AM. It is therefore possible to produce parts with added values for the customer, light weight vehicle designs, hence reduced emissions, and ondemand manufacturing [23]. Other benefits including reduced time to market are presented in Table 2. However, AM is still an expensive process and is not suitable, to date, for all applications. Manufacturing of large production batches, low cost materials and simple part geometries that can be machined from blocks are factors that still favours conventional manufacturing methods [5]. 
Table 2. Benefits for additively manufactured parts [23,24]

\begin{tabular}{|l|l|}
\hline Customized parts & Added value \\
\hline Functional design & $\begin{array}{l}\text { Improved performance by for ex- } \\
\text { ample internal cooling channels }\end{array}$ \\
\hline Light weight designs & $\begin{array}{l}\text { Reduced fuel consumption and re- } \\
\text { duced emissions }\end{array}$ \\
\hline $\begin{array}{l}\text { Reduced material waste, as- } \\
\text { sembly (several parts consoli- } \\
\text { dated into one) and tooling }\end{array}$ & Reduced cost \\
\hline $\begin{array}{l}\text { Reduced development and } \\
\text { manufacturing time }\end{array}$ & $\begin{array}{l}\text { Shorter time to market, on-demand } \\
\text { manufacturing }\end{array}$ \\
\hline On-demand manufacturing & Reduced transport and storage cost \\
\hline On-site manufacturing & $\begin{array}{l}\text { Shorter downtime for customer, se- } \\
\text { cured supply chain }\end{array}$ \\
\hline
\end{tabular}

Moreover, AM has the potential to be a market disrupter, changing the well-established supply chains of the industry [23] by reducing the number of suppliers in a supply chain and shift the manufacturing from one central to many local locations [24]. Moreover, local on-demand manufacturing would lower transportation and storage costs [24]. This requires, however, that the local AM manufacturer has expertise in many different areas for example, materials, computer aided design (CAD), metrology, automation and post processing [23].

In short, AM is to date most beneficial for high value or low volume products as the main potential is in manufacturing of design solutions that are not possible or too expensive to manufacture with conventional methods [23].

\subsection{AM in Aerospace}

AM is generally considered to have great potential for aerospace applications. In addition to reduced emissions, lower weight and/or higher performance would, for an aircraft, like the Saab JAS 39E Gripen in Figure 4 , also give increased payload, i.e. amount of weight that could be carried, and extended flight range which is beneficial for both civilian and military aircraft. Since many aircraft have a lifetime of more than 30 years 
there are, furthermore, great challenges and costs connected to maintaining spare parts, tools and inventory for that period of time [25]. AM has the potential to be used for on-demand spare part manufacturing and repair in a "timely and cost-efficient manner" [25]. Local, on-site or infield, manufacturing of spare parts would also lead to reduced downtime due to maintenance [26] and in military applications also ensure a secure supply of spare parts in a crise situation when ordinary supply chains could have been shut down.

The route forward seems obvious, in relation to the possible benefits, but there are, however, technical challenges that need to be solved before AM could be fully introduced into critical aerospace applications including:

- Improved reproducibility, including quality variation between build or AM-machines [23]

- Improved surface roughness and dimensional tolerances [23]

- Improved fatigue properties [26]

- NDT methods for flaws and defects [26]

- Simulation methods to predict quality and properties of an entire AM build.

- Education of engineers to an AM mindset and to adopt new design tools for AM.

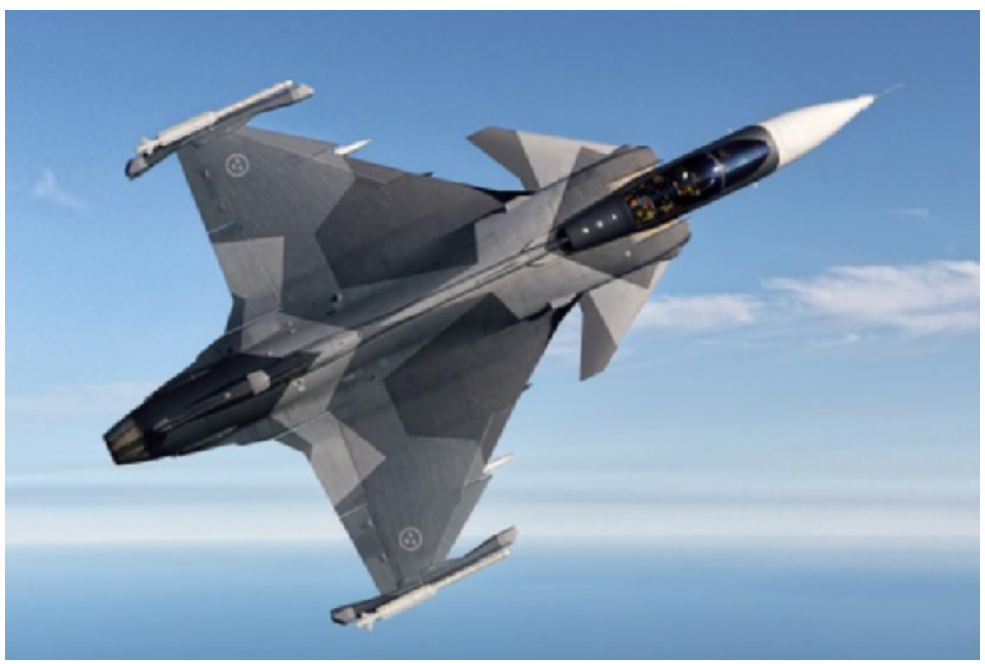

Figure 4. The Saab JAS 39E Gripen aircraft. Photo and copyright: Saab AB. 


\section{Titanium Alloys}

This chapter provides general information about the titanium alloy Ti6Al4V addressed in this thesis. Alloy Ti6Al4V is to date the most widely used titanium alloy by far and correspond to more than $50 \%$ of the annual titanium production [27]. Aerospace and medical industry are two of the major customers and in 2006, aerospace used $44 \%$ of the world production of titanium in which Ti6Al4V was the most commonly used alloy [28].

When it comes to metal AM, Ti6Al4V is one of the alloys that have been investigated the most, which can be attributed to a large range of possible business cases of advanced industrial parts with low production volumes [5]. Additively manufactured Ti6Al4V has the same chemical composition, see Table 3, as Ti6Al4V produced from conventional production forms like for example casting, bar or forging. However, material behaviour for additively manufactured Ti6Al4V can still be very different compared to the behaviour of Ti6Al4V from conventional product forms. The different behaviour can both be attributed to differences in microstructure [29][30][31] but also due to effects of the rough as-built AM surface which affects both fatigue behaviour [29][31][32][33] and static properties [31][32][34].

Table 3. Nominal chemical composition, according to ASTM F2924-14, for Ti6Al4V manufactured by powder bed fusing

\begin{tabular}{|c|c|c|c|c|c|c|c|c|c|c|}
\hline & $\mathrm{Al}$ & $\mathrm{V}$ & $\mathrm{Fe}$ & $\mathrm{O}$ & $\mathrm{C}$ & $\mathrm{N}$ & $\mathrm{H}$ & $\mathrm{Y}$ & Other & $\mathrm{Ti}$ \\
\hline $\begin{array}{c}\text { Min, } \\
\%\end{array}$ & 5.50 & 3.50 & - & - & - & - & - & - & - & $\begin{array}{c}\text { re- } \\
\text { main- } \\
\text { der }\end{array}$ \\
\hline $\begin{array}{c}\text { Max, } \\
\%\end{array}$ & 6.75 & 4.50 & 0.30 & 0.20 & 0.08 & 0.05 & 0.015 & 0.005 & 0.40 &
\end{tabular}

\subsection{Microstructure}

The AM PBF production methods are complex and include both layerby-layer manufacturing and repeated heating, see Figure 3, of the material [5]. The heat cycle, that includes both heating and cooling, is rapid and grain formation is therefore very fast even though the grains do not have time to grow further due to the quick cooling, in which cooling rates of $10^{4} \mathrm{~K} / \mathrm{s}$ have been reported for L-PBF [5]. During each heat cycle, the 
laser or electron beam melts simultaneously both a new layer of unmelted powder and several layers of already solidified material. This gives a continuous microstructure across the layers and the growth of columnar grain structure is promoted in the vertical building direction [5].

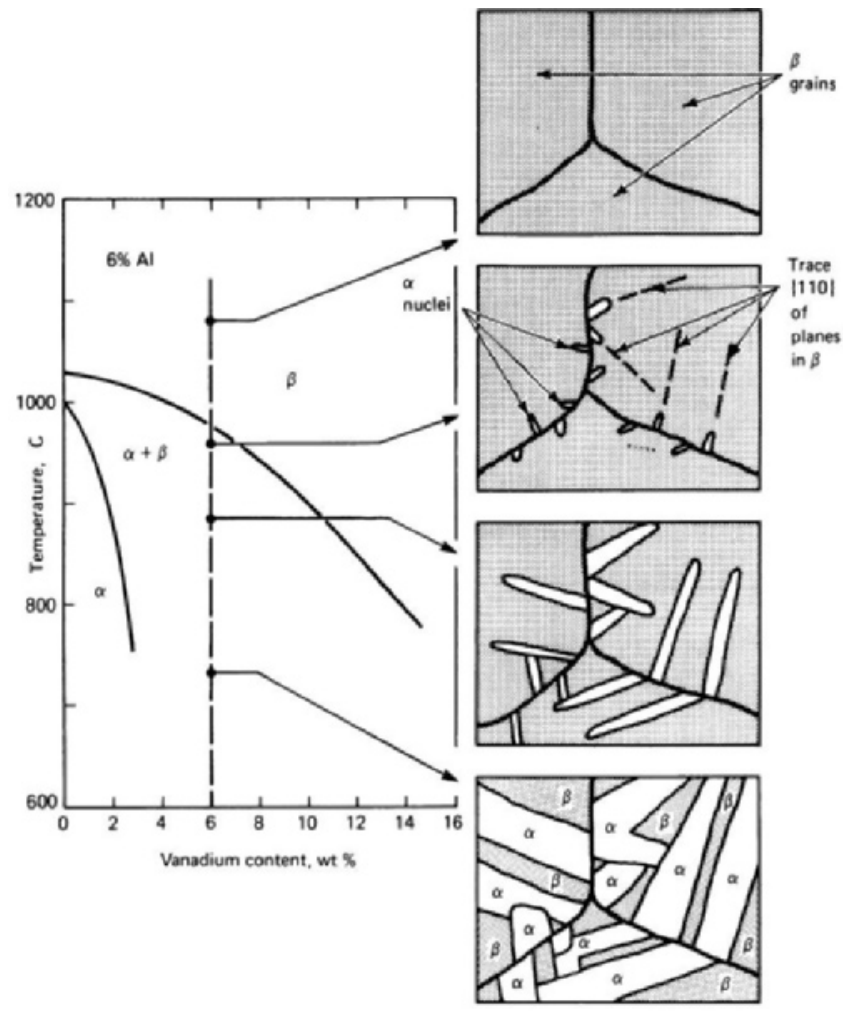

Figure 5. Phase diagram for Ti6Al4V and schematic microstructure at intermediate temperatures during slow cooling from a temperature above the $\beta$-transus showing $\alpha$-phase (white) and $\beta$-phase (dark).

Image is used with permission of ASM International, from Donachie [35] 2000@; permission conveyed through Copyright Clearance Center, Inc.

\subsubsection{Conventional Produced Ti6Al4V}

The microstructure of Ti6Al4V from conventional product forms is achieved by refinement of the grains during cooling from the $\beta$-phase or the $\alpha+\beta$ phase region followed by ageing heat treatment to dissolve the martensite formed at quenching. During slow cooling from the $\beta$-region the microstructure starts to form $\alpha$-phase below the $\beta$-transus $\left(980^{\circ} \mathrm{C}\right)$. The $\alpha$-phase forms as plates and together with the remaining $\beta$-phase it forms a Widmanstätten structure which is illustrated in Figure 5 [35]. When cooled quickly from temperatures above the $\beta$-transus $\left(980^{\circ} \mathrm{C}\right)$ the $\beta$-phase could decompose to martensitic $\alpha$ ' or $\alpha$ ' structure with only a small amount of remaining $\beta$. The $\beta$-phase can remain in the structure even after rapid cooling since the end of the martensitic transformation, 
$\mathrm{M}_{\mathrm{f}}$, is below room temperature $\left(<25^{\circ} \mathrm{C}\right)$ for this alloy and not all $\beta$ are therefore transformed to $\alpha$ ' or $\alpha$ '. Subsequent heat treatment to achieve a more ductile material is common, for example mill annealing at $730^{\circ} \mathrm{C}$ for $4 \mathrm{~h}$, which gives a microstructure with globular crystals of $\beta$ within an $\alpha$-matrix [35].

\subsubsection{E-PBF Produced Ti6A14V}

The bulk material of Ti6Al4V produced by E-PBF has a pronounced columnar grain structure in the vertical building direction, originating from $\beta$-grains that have grown continuous through multiple building layers, see Figure 6 [36][37][38]. Close to the surface, however, there are instead fine tilted columnar grains, as illustrated by Figure 6 , due to grain nucleation from the partially melted powder particles on the surface followed by inward grain growth along the meltpool untill contact with an upward growing $\beta$-grain [38].

The microstructure generally consists of $\alpha$ (hcp) $+\beta$ (bcc) microstructure [29]. The $\alpha$-phase is acicular (needle like) or plate like and has generally a fine and evenly distributed Widmanstätten (basketweave) structure [37]. The microstructure of E-PBF material, see Figure 7a, subjected to hot isostatic pressing (HIP) has been found to be courser but otherwise similar to the microstructure of E-PBF without heat treatment [37].

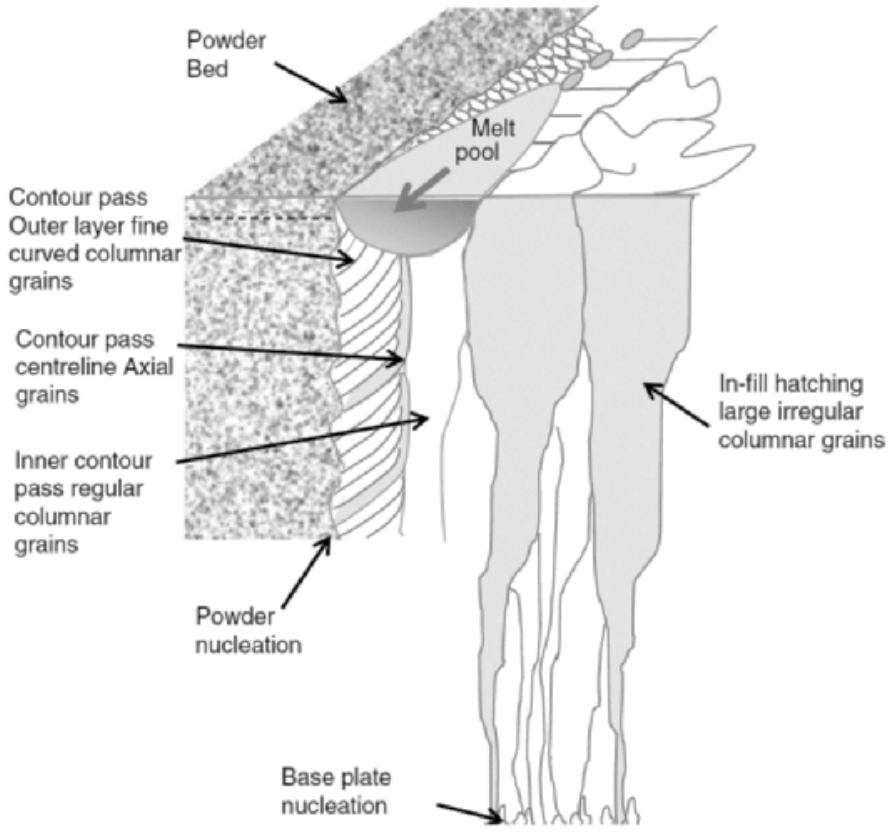

Figure 6. Grain structure of E-PBF Ti6Al4V. Image by Antonysamy et al. [38] licensed

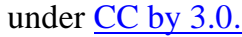



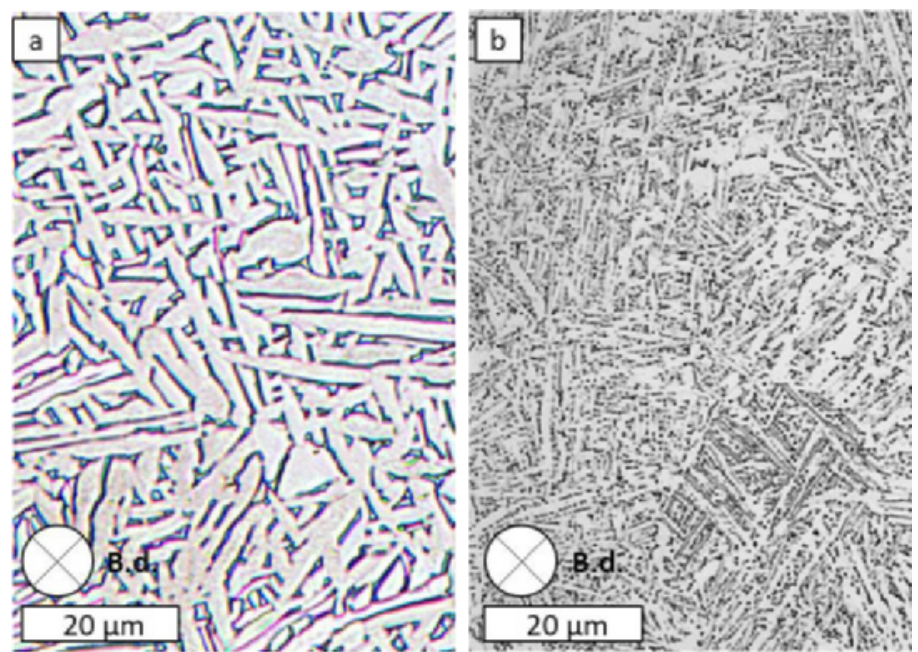

Figure 7. Typical microstructures of Ti6Al4V manufactured by a.) E-PBF (HIP:ed), b.) L-PBF (stress relieved). B.d. = build direction

\subsubsection{L-PBF Produced Ti6Al4V}

Ti6Al4V material produced with L-PBF shows somewhat different microstructure characteristics compared to E-PBF material as illustrated in Figure $7 \mathrm{a}-\mathrm{b}$. The higher cooling rates of L-PBF give a finer microstructure, compared to E-PBF material, but the high rate also contributes to considerable higher residual stresses if no post heat treatment is performed [39].

The L-PBF material has a pronounced columnar grain structure in the vertical building direction for the bulk region [31][39], similar to the EPBF microstructure, but finer and more equiaxed grains closer to the surface [40]. If no post heat treatment is performed for L-PBF material, the microstructure generally consists of $\alpha-\alpha^{\prime}$ (martensite) microstructure [29]. The columnar grains are filled with $1-2 \mu \mathrm{m}$ wide martensitic laths that are transformed from prior $\beta$-grain boundaries [30]. L-PBF material that is post heat treated with stress relieving, at $700-730^{\circ} \mathrm{C}$ for $1-2 \mathrm{~h}$, can either have martensitic $\alpha$ ' microstructure or a mixture of $\alpha+\beta$ if the temperature exposure is large enough [31][41]. If the L-PBF material is annealed at higher temperatures the $\alpha$ ' is transformed to $\alpha+\beta$ microstructure [31]. 


\subsection{Surface Roughness}

The rough as-built surface of PBF material is generally rougher than both wrought and cast material due to AM effects of partially melted powder particles that are attached to the surface, stair stepping for angled surfaces and balling which is splashing of small liquid droplets on the top surface [42]. The surface roughness can be divided into a primary roughness and a secondary roughness in which the primary is responsible for the vast majority of the surface roughness magnitude [43][44]. The primary roughness is connected to the layer thickness for surfaces parallel to the build direction and connected to scanning tracks for surfaces perpendicular to the build direction while the secondary is connected to partially melted powder particles attached to the surface [44]. As illustrated in Figure 8, the surface of E-PBF material is considerable rougher compared to L-PBF material which can be attributed the larger layer thickness and larger powder particle sizes of the E-PBF material [30].
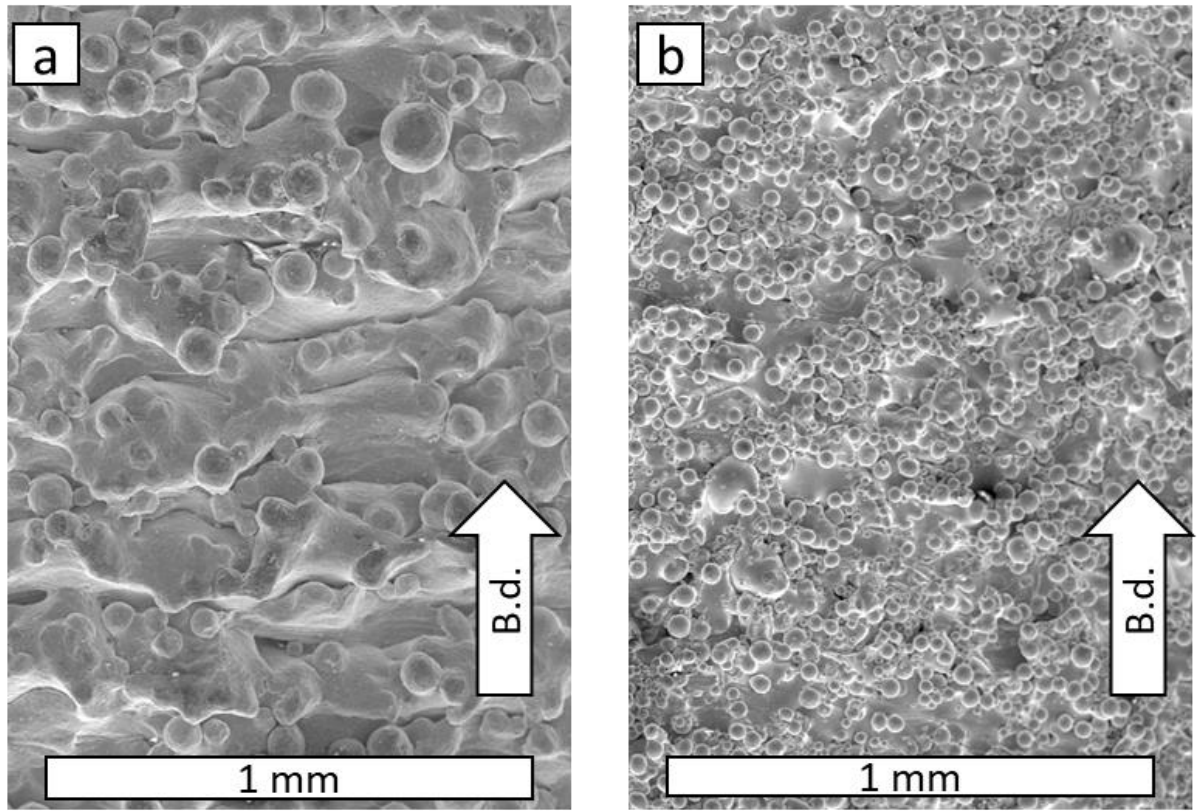

Figure 8. Rough as-built surface, a.) E-PBF, b.) L-PBF, B.d.=build direction 


\subsection{Internal Material Defects}

\subsubsection{Porosity}

Spherical microporosity, see Figure 9, in both E-PBF and L-PBF material originates generally from the gas atomized powder which could contain entrapped microporosity of argon gas bubbles [37][45]. However, pores can also be created during the PBF process if the energy density is too high and causes vaporization of the molten metal [46]. Cavities is formed if the gas bubbles created during vaporization get trapped underneath the surface and these pores are referred to as keyhole porosity [46]. If appropriate AM process parameters are used a pore free material is generally achieved with a relative density above $99 \%$ [47].

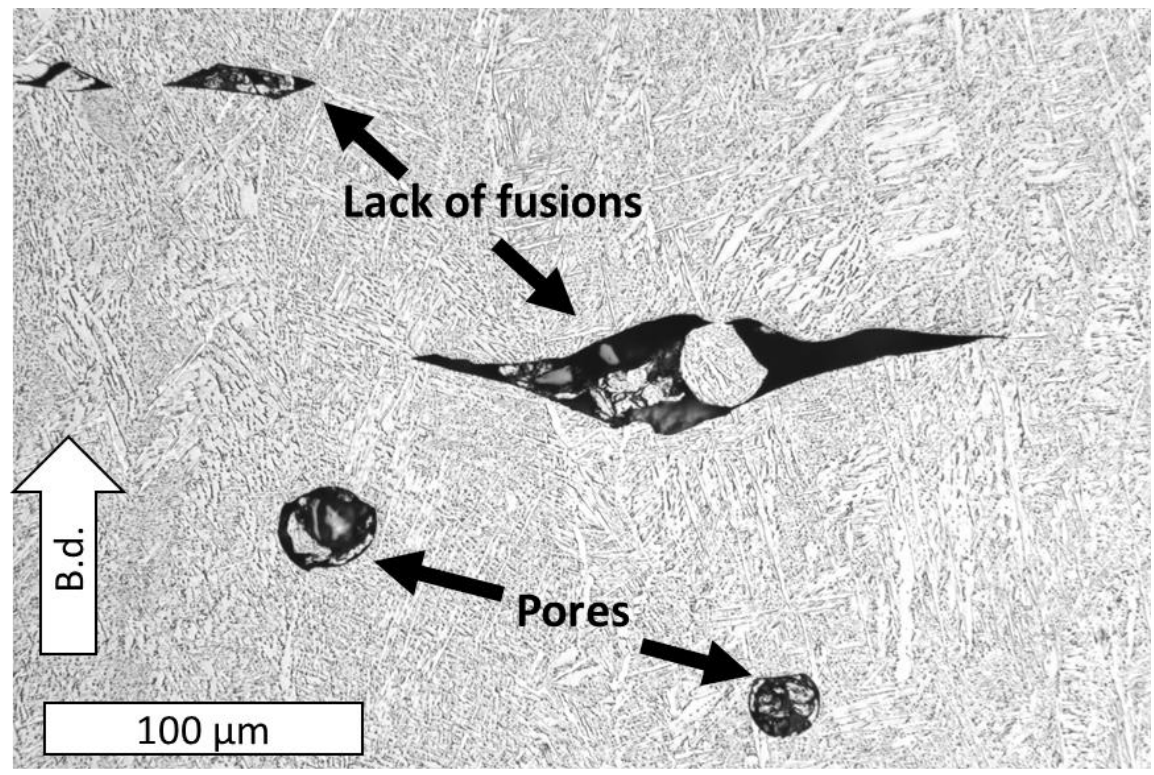

Figure 9. Spherical porosity and lack of fusion defects.

\subsubsection{Lack of Fusion}

The most severe internal defect in AM materials, from a fatigue point of view, is lack of fusion (LOF), see Figure 9. LOF defects are generally created if there is insufficient energy to properly melt and fuse the new layer to the previous layer during the manufacturing process [45][48]. 
Other factors that could promote LOF could be non-optimal focus calibration of the beam, unsuitable parameters of beam current and scan speed, non-optimal settings for powder deposition or powder with to high content of contaminations.

LOF:s are generally aligned perpendicular to the building direction and form primarily along the interlayer boundaries in the interface region between the material melted with contour-parameters and material melted with hatching [45]. The LOF defects act both as stress concentrations and reduces the load-bearing area when the samples are loaded in the building direction. This reduces the fatigue and static strength in building direction as well as the elongation to fracture [49]. For fatigue specimens with machined surfaces the fatigue cracks generally initiate from internal LOF:s and therefore an elimination of LOF:s can, through process optimization or HIP treatment, increase the fatigue life [45]. 


\section{Materials, Experiments and Modelling}

\subsection{Material}

\section{Paper I-V}

Test specimens of titanium alloy Ti6Al4V were manufactured using both L-PBF and E-PBF processes. A total of three L-PBF and two E-PBF builds were manufactured, see Table 4 , having only samples from one single build, per process, for each study to avoid build-to-build variations. All builds were manufactured with the standard build parameters recommended by EOS, GE Additive (Arcam), Renishaw respectively. Test specimens were manufactured either directly to final shape, i.e. with rough as-built surface or as blocks/cylinders and machined to final shape as illustrated by Figure 10 and Figure 11. Wrought Ti6Al4V bar material $(\varnothing 30 \mathrm{~mm})$, in mill annealed condition, was used for reference fatigue tests. For more detailed process parameters please refer to appended $\mathrm{Pa}$ pers $I-V$.

Table 4. Overview of AM builds and heat treatments relative to the appended papers.

\begin{tabular}{|c|c|c|c|c|c|}
\hline Paper & Process & Equipment & $\begin{array}{c}\text { Layer } \\
\text { thickness }\end{array}$ & $\begin{array}{c}\text { Heat } \\
\text { treatment }\end{array}$ & $\begin{array}{c}\text { Hot Isostatic } \\
\text { Pressing (HIP) }\end{array}$ \\
\hline \multirow{4}{*}{$\begin{array}{l}\text { Paper } \\
\text { I \& II }\end{array}$} & \multirow[t]{2}{*}{ L-PBF } & \multirow{2}{*}{$\begin{array}{c}\text { EOS } \\
\text { M } 290\end{array}$} & \multirow[t]{2}{*}{$30 \mu \mathrm{m}$} & \multirow{2}{*}{$\begin{array}{c}650^{\circ} \mathrm{C} \\
3 \mathrm{~h}\end{array}$} & $\begin{array}{c}920^{\circ} \mathrm{C}, 2 \mathrm{~h} \\
1000 \mathrm{bar}\end{array}$ \\
\hline & & & & & No \\
\hline & \multirow{2}{*}{ E-PBF } & \multirow{2}{*}{$\begin{array}{l}\text { Arcam } \\
\text { A2 }\end{array}$} & \multirow{2}{*}{$50 \mu \mathrm{m}$} & \multirow{2}{*}{ No } & $\begin{array}{c}920^{\circ} \mathrm{C}, 2 \mathrm{~h} \\
1000 \mathrm{bar}\end{array}$ \\
\hline & & & & & No \\
\hline \multirow{2}{*}{$\begin{array}{l}\text { Paper } \\
\text { III \& IV }\end{array}$} & L-PBF & $\begin{array}{l}\text { EOS } \\
\text { M } 280\end{array}$ & $60 \mu \mathrm{m}$ & $\begin{array}{c}730^{\circ} \mathrm{C} \\
2 \mathrm{~h}\end{array}$ & No \\
\hline & E-PBF & $\begin{array}{l}\text { Arcam } \\
\text { A2XX }\end{array}$ & $70 \mu \mathrm{m}$ & No & $\begin{array}{c}920^{\circ} \mathrm{C}, 2 \mathrm{~h} \\
1030 \mathrm{bar}\end{array}$ \\
\hline Paper V & L-PBF & $\begin{array}{c}\text { Renishaw } \\
500 Q\end{array}$ & $60 \mu \mathrm{m}$ & $\begin{array}{c}850^{\circ} \mathrm{C} \\
4 \mathrm{~h}\end{array}$ & No \\
\hline
\end{tabular}




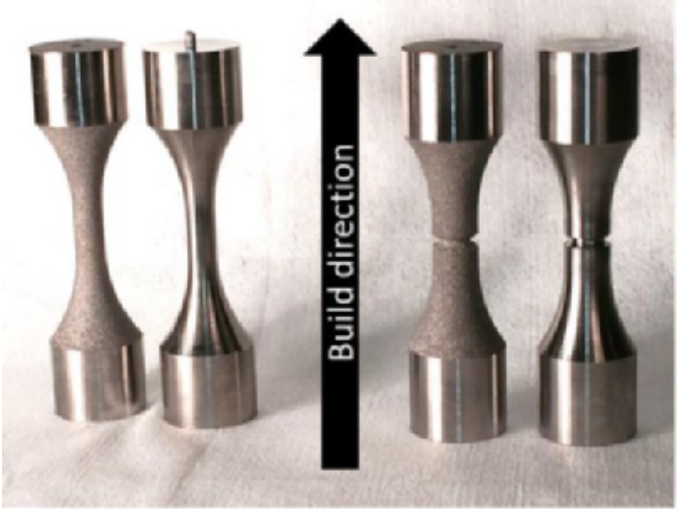

a.

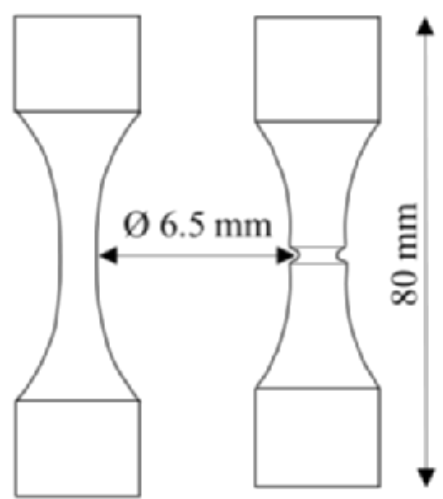

b.

Figure 10. Fatigue test specimens, a.) notched and smooth fatigue specimens in asbuilt and machined conditions, b.) nominal dimensions for fatigue specimens

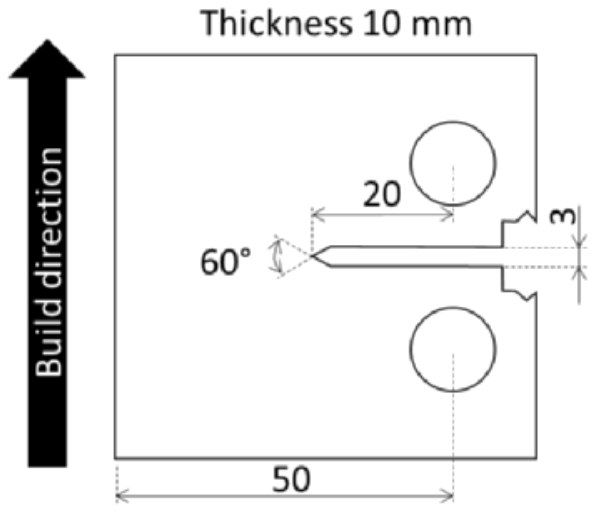

a.
Thickness $15 \mathrm{~mm}$

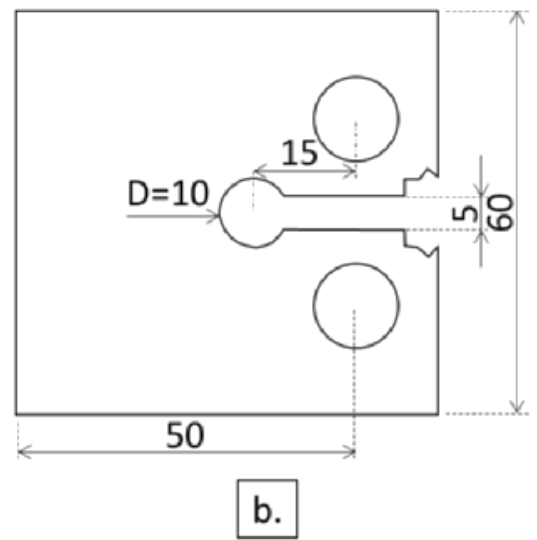

Figure 11. Final geometry of FCG specimens, a.) compact-tension (CT) specimen, b.) keyhole specimen.

\subsection{Post Processing}

\subsubsection{Heat Treatment}

\section{Paper I-V}

The L-PBF specimens were all heat treated to reduce the residual stresses inherit from the AM process using the times and temperatures presented 
in Table 4. E-PBF specimens are continuously annealed during the AM process and require therefore no post heat treatment for stress relieving. HIP heat treatment in which the samples are compressed, using a chamber with highly pressurized argon gas, in order to close internal defects was applied to selected test series to determine the effect of HIP and to reduce the risk of cracks starting from internal defects when effect of the surface roughness was investigated.

\subsubsection{Surface Post Processing}

Paper III \& IV

All as-built surfaces were brushed or sandblasted (L-PBF) or blasted with titanium particles (E-PBF) to remove loosely bound powder particles. Since the main benefit of AM is the freedom of design, one wants to avoid $100 \%$ machining of the part which would reduce AM to a near-net-shape manufacturing process and result in parts with conventionally machined geometries. Specimens connected to Paper III \& IV were therefore surface post processed with other methods to improve the fatigue strength by reducing the roughness and/or introducing compressive residual stresses using the following processes (for more detailed process parameters please refer to appended Paper III \& IV):

Centrifugal finishing: The parts are placed in a rotating barrel together with abrasive media. The relative movement between parts and media wears down any protruding features leaving the surface in a polished condition. However, geometrical features, e.g. corners, will be rounded as the surface is smoothen which requires a balanced process between loss of geometrical features and surface removal. Vibratory-, barrel- or tumble finishing have all similar approach as centrifugal finishing [50].

Shot peening: The part is bombarded by steel shots that introduce compressive residual stresses in the near surface region by cold working of the material. The surface roughness of the rough as-built AM surface is furthermore smoothened during the process. The samples were shot peened according to standard AMS2430 using $200 \%$ coverage and measuring an Almen intensity of 0.0093 ' A. This process requires line of sight to the treated surface.

Laser polishing: The surface of the part is re-melted to a depth of 50-200 $\mu \mathrm{m}$ and any protruding surface peaks are melted and re-flown into surface 
valleys which reduces the surface roughness. This process requires line of sight to the treated surface.

Laser shock peening: The part is covered by a thin layer of water which is vaporized by a laser beam. The resulting plasma pulse expands like a shock wave and introduces compressive stresses by cold working similar to shot peening. A pulsed laser with power density of $5.3 \mathrm{GW} / \mathrm{cm}^{2}$ was used. This process requires line of sight to the treated surface.

Linishing: The surface of the part is polished by high-speed brushes which are robot controlled to ensure constant contact force and high precision across the part.

\subsection{Tensile Testing}

\section{Paper I, III \& V}

Room temperature tensile tests were performed on polished specimens using a servo hydraulic test rig with an Instron 8800 control system. An extensometer was used during the first part of the test to capture the yield strength at $0.2 \%$ offset and the elastic modulus. The test specimens were loaded with a rate of $0.004 \mathrm{~mm} / \mathrm{s}$ which fulfils the requirements in test standard ISO 6892-1.

\subsection{Microscopical Investigations}

Paper I-V

Light optical microscopy was used to investigate microstructure and internal defects of cut-up sections of test samples. The samples were etched with Kroll's reagent, consisting of $1.25 \%$ hydrofluoric acid (48 \% concentration) and $3 \%$ nitric acid, to reveal the microstructure. The size of the $\alpha$-lath in the microstructure and amount of internal porosity were analysed using the open source image processing software Image J [51]. Stereomicroscopy and scanning electron microscopy (SEM) using a HITACHI SU-70 field emission gun operation at $15 \mathrm{kV}$ were used to investigate the fracture surfaces and the crack initiation points of the fatigue specimens. 


\subsection{Hardness Testing}

Paper 1 \& III

Vickers (HV5) and Knoop (HK0.1) hardness testing were performed using a Struers Durascan hardness test equipment. All hardness indents fulfilled the requirements in test standard ASTM E384 on minimum distance to outer edge and adjacent hardness indent.

\subsection{Surface Roughness Investigations}

Paper I, III \& IV

The surface roughness was determined using two different methods:

Image analysis (Paper I): The surface roughness parameters were determined using image analysis of cut-up sample. Light optical microscopy was used to take images with a sampling length of approximate $15 \mathrm{~mm}$. An inhouse Matlab script [52] was thereafter used to transform the image to a black-and-white binary image and then acquire the surface texture profile and associated surface roughness parameters e.g. $R v$ (maximum profile valley depth within a sampling length) and $R a$ (arithmetical mean deviation within a sampling length).

Focus variation microscopy (Paper III \& IV): An Alicona SL focus variation microscope was used for surface texture measurements over an area of $2 \mathrm{~mm}^{2}$. The measurements, which are used to produce 3D-images of the surface, were further analysed using Infinite Focus Measurement Suite by Alicona and MountainsMap by Digital Surf to determine the surface roughness parameters. The surface texture measurements by focus variation microscopy were performed and evaluated by Manufacturing Technology Centre (UK) and University of Nottingham (UK).

\subsection{Surface Residual Stress Investigations}

\section{Paper III}

An X-ray diffraction instrument from Stresstech, XStress 3000 G2R equipped with a titanium $\mathrm{X}$-ray tube was used to determine the surface residual stresses in the Z-direction (build direction) for both rough asbuilt and post processed surfaces. The residual stress was measured in accordance with standard SS-EN 15304 by Research Institutes of Sweden (RISE) which is an accredited laboratory. 


\subsection{Fatigue Testing}

Paper I-IV

Fatigue testing has been performed with load control using a servo hydraulic fatigue test rig with an Instron $\pm 50 \mathrm{kN}$ load cell and an Instron 8800 control system. The tests were performed at room temperature with test specimens with nominal dimensions, before surface post processing, according to Figure 10b. All fatigue tests have been performed with the load applied in the specimen's build direction with either a smooth geometry, with a stress concentration $\mathrm{K}_{\mathrm{t}}=1$, or with a notched geometry, with a stress concentration $\mathrm{K}_{\mathrm{t}}=2.5$, see Figure 10a-b.

\subsubsection{Constant Amplitude Loading}

\section{Paper I \& III}

Fatigue testing with constant amplitude loading was performed with 20 $\mathrm{Hz}$ frequency at stress ratio $\mathrm{R}=0.1$.

\subsubsection{Variable Amplitude Loading}

\section{Paper II \& IV}

Fatigue testing with variable amplitude loading was performed with 10 $\mathrm{Hz}$ frequency using a fighter aircraft wing bending spectrum called ShortFALSTAFF (Fighter Aircraft Loading STAndard For Fatigue) which is illustrated in Figure 12. FALSTAFF was originally created by NLRNetherlands, LBF-Germany, IABG-Germany and F\&W-Switzerland [53] and further developed by CEAT [54] into the Short-version which has about $50 \%$ less cycles, but still generates almost the same cumulative damage, as the original sequence. One Short-FALSTAFF sequence has 9006 cycles and corresponds to 200 simulated flights. The ShortFALSTAFF load sequence is scaled to different maximum net section peak stresses and the test specimens are then loaded with the sequence repeatedly until failure occurs. 


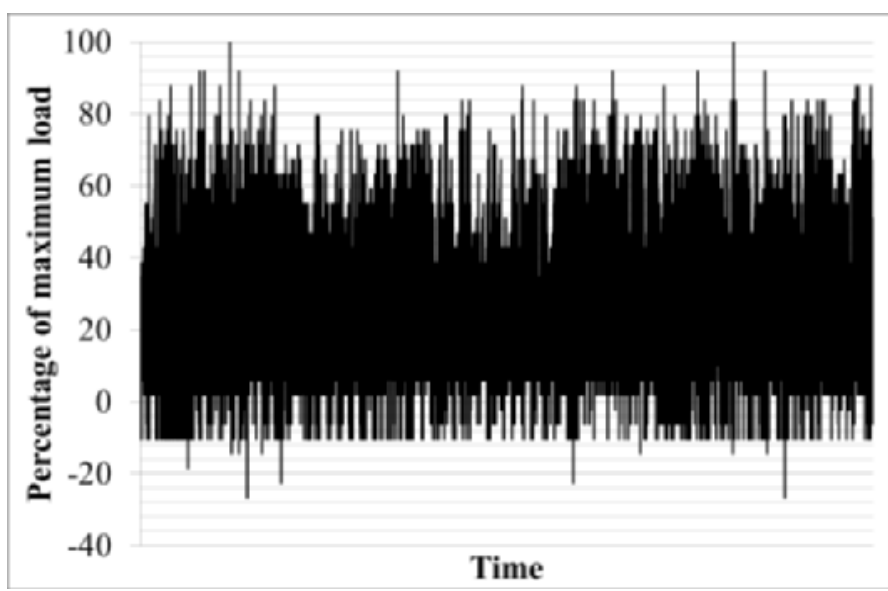

Figure 12. One sequence of the short-FALSTAFF with 18012 turning points. This im-

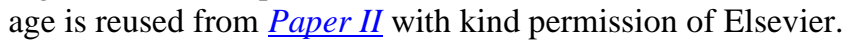

\subsection{Fatigue Life Prediction Models}

\section{Paper II \& IV}

A cumulative damage approach, using Palmgren-Miner's rule [37,38] presented in Eq. 1, has been used to predict the fatigue life of the variable amplitude loaded test series. An overview of the evaluation process is presented in Figure 13.

$D=\sum_{i=1}^{k} \frac{n_{i}}{N_{i}}$

$\mathrm{D}$ is the cumulative damage, $\mathrm{n}_{\mathrm{i}}$ is the numbers of load cycles of $\mathrm{i}$-type and $\mathrm{N}_{\mathrm{i}}$ is the number of $\mathrm{i}$-type load cycles that correspond to fatigue failure.

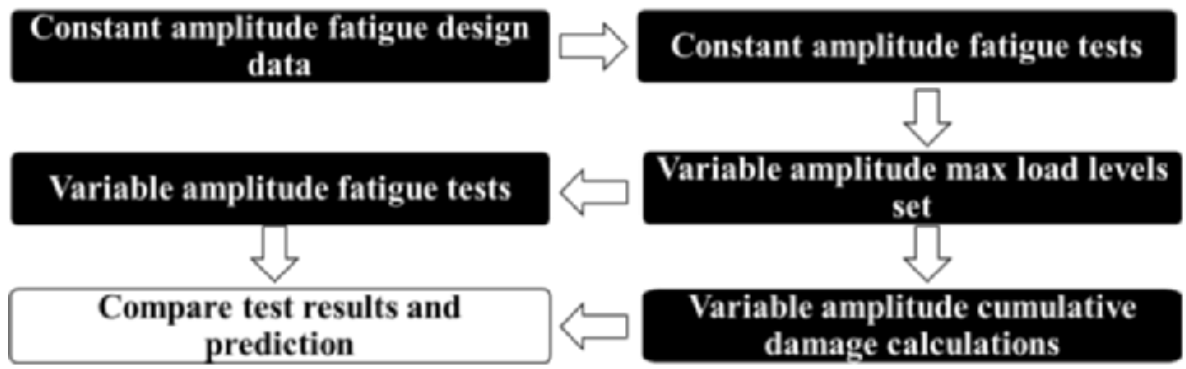

Figure 13. An overview of the evaluation procedure for fatigue life predictions with variable amplitude loading. 
The constant amplitude test series with additively manufactured Ti6Al4V that were tested in Paper I and III were manually curve fitted to Wöhler curves. Wöhler curves for investment cast Ti6Al4V, from the Saab Aeronautics material database, were then scaled to fit these curves using the adjustment function schematic illustrated in Figure 14. The same adjustment function was then applied to the full Haigh diagram for investment casting, from the same database, resulting in a Haigh diagram for each AM test series that could be used for cumulative damage calculations.

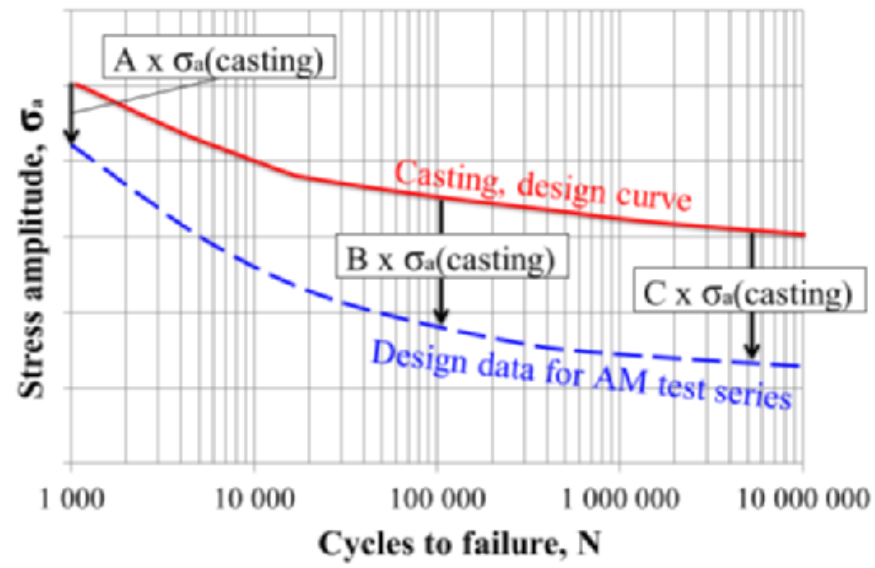

Figure 14. Schematic illustration of the design data adjustment for Wöhler curves. A, B and $\mathrm{C}$ are constants that varies between AM test series.

The distribution of the rain-flow counted cycles in one Short-FALSTAFF load sequence is presented in Figure 15. Constant amplitude Wöhler curves are extracted from each data point in Figure 15 to calculate the fatigue life for those rain-flow counted cycles. The Wöhler curves are extracted in three different ways:

1.) Stress ratio $-1 \leq \mathrm{R} \leq 0$ : by interpolation of stress amplitude $\left(\sigma_{\mathrm{a}}\right)$

2.) Stress ratio $R<-1$ : by using constant mean stress $\left(\sigma_{m}\right)$

3.) Stress ratio $\mathrm{R}>0$ : by using constant minimum stress $\left(\sigma_{\min }\right)$ 


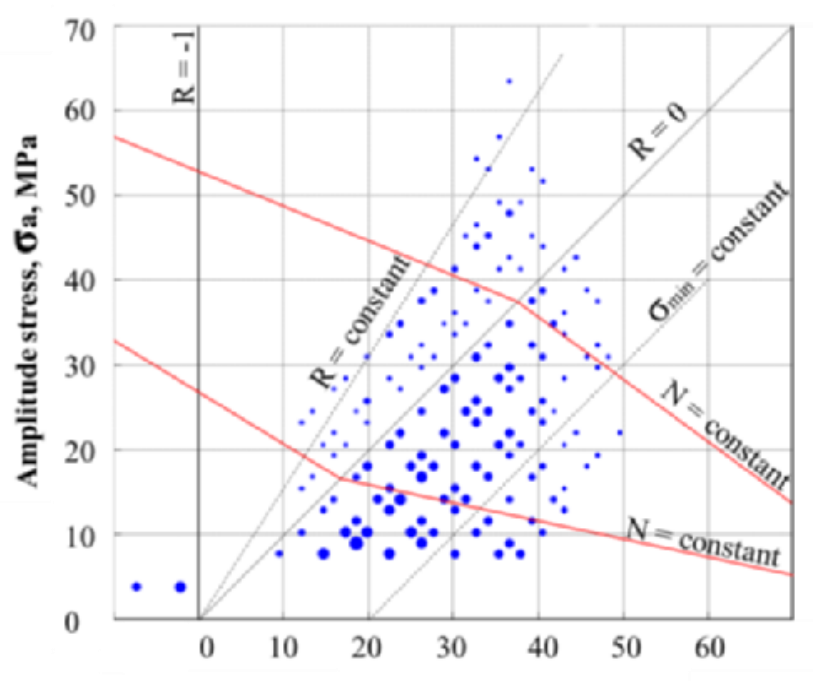

Mean stress, $\sigma \mathrm{m}, \mathrm{MPa}$
Figure 15. The distribution of one ShortFALSTAFF load sequence. The amount of rain-flow counted cycles is represented by the size of the data points, i.e. larger points represent more cycles. This image is reused from Paper II with kind permission of Elsevier.

\subsection{Fatigue Crack Growth Testing}

Paper $V$

Room temperature fatigue crack growth (FCG) testing was performed with a frequency of $10 \mathrm{~Hz}$ using an MTS 858 Mini Bionix hydraulic test frame with a $10 \mathrm{kN}$ hydraulic actuator. An EDC 580 DOLI control system was used to control the testing and a Crack Opening Displacement (COD) transducer, with $2 \mathrm{~mm}$ travel length, to measure the displacement. The tests were performed with stress ratio $\mathrm{R}=0.1$ or $\mathrm{R}=0.5$ using two types of tests specimens, CT or keyhole, with dimensions according to Figure 11ab.

The CT specimens, which were in accordance with ASTM E647, had a crack propagating through the specimen thickness. In contrast, keyhole specimens had a part-through crack that started from a point defect in the centre of the radius and propagated in both the width and the depth direction as illustrated in Figure 16a-b. The keyhole specimen tests were all stopped before the crack reached through the entire specimen thickness, i.e. the total crack length (2c) was less than $15 \mathrm{~mm}$. 
The crack length of the keyhole specimens was monitored by a camera, in addition to COD, that took a photograph of the crack in notch, see Figure 16a, between every block of 2000 load cycles. The keyhole tests were then paused for 60 seconds and kept at $85 \%$ of the maximum load to allow the camera to capture an image of the crack. The crack length at the surface, in the width direction, was evaluated using the open source software Image J [51].
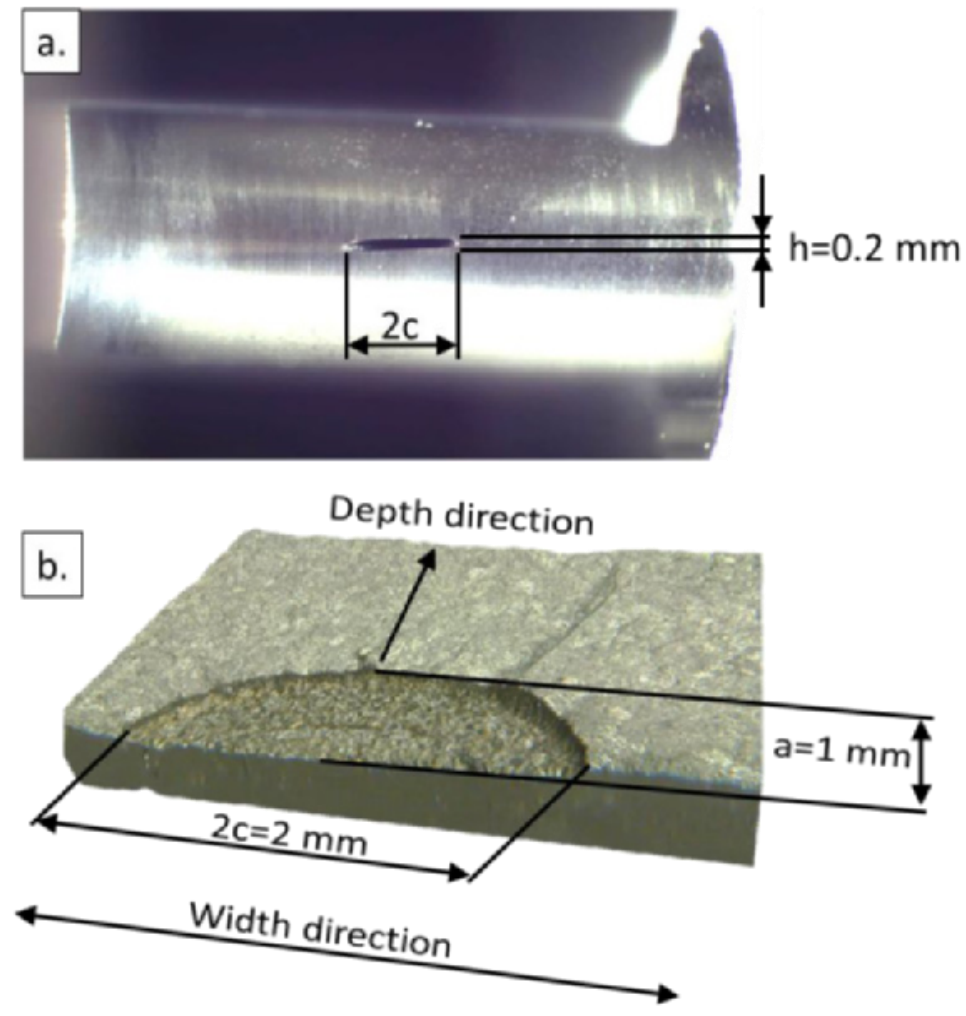

Figure 16. Keyhole specimen, a.) start defect in the notch, b.) start defect seen on fracture surface. This image is reused from Paper $V$ with kind permission of Elsevier. 


\subsection{Fatigue Crack Growth Prediction Models}

\section{Paper $V$}

FCG relationships for CT specimens comprising stress intensity factor $(\mathrm{K})$, geometry, displacement $(\delta)$, force $(\mathrm{P})$ and crack length (a) are given by ASTM E647.

For keyhole specimens the relation between the surface crack length (c) and depth crack length (a) need to be known prior to testing and in this work solved with Finite Element (FE) method. The FE-analyses of the keyhole specimen, with a part-through crack in the notch, were performed using Trinitas [55], an integrated graphical stand-alone FE-environment. Only a quarter of the geometry needs to be modelled, due to symmetry, as illustrated in Figure 17a.

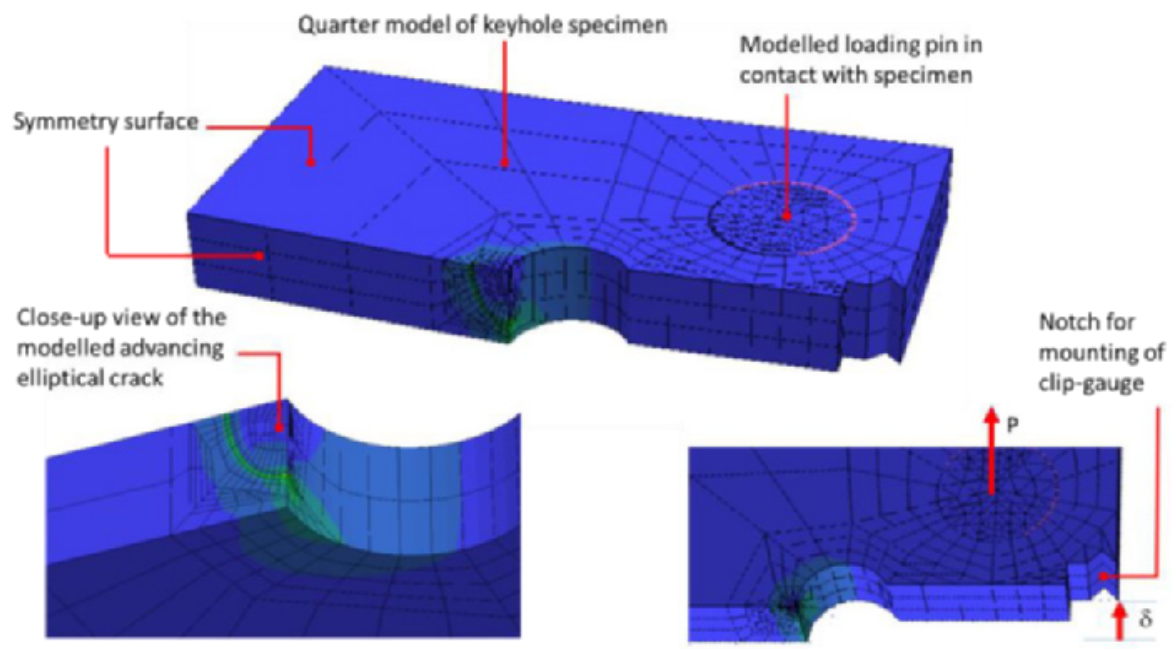

Figure 17. a.) FE-model of a quarter of the keyhole specimen, b.) compliances and crack length relationship, c.) advancing elliptical crack in close-up view. $\mathrm{P}=$ force, $\delta=$ displacement. This image is reused from Paper $V$ with kind permission of Elsevier.

Modelling of the crack surroundings was performed using a mesh that adapts as the crack size and form changes during crack propagation. The virtual crack extension method [56] was used to determine the stress intensity factors. An indirect method to measure the crack length in the hidden depth direction is to use the compliance (C) which is defined as the 
displacement divided by the force $\mathrm{C}=\delta / \mathrm{P}$ and determined by FE-analyses for a range of elliptical cracks of specific lengths and shapes.

When the compliance, in Figure 17b, and the crack aspect ratio, in Figure 18 , have been determined, the crack lengths a and c can be predicted for each FCG test using the displacement $(\delta)$ and force $(\mathrm{P})$ data obtained from the actual FCG test. Finally, the FCG rates are determined by evaluating the slope of the surface crack length (c) versus number of cycles for each test.

For more detailed description of the modelling please refer to appended Paper V.

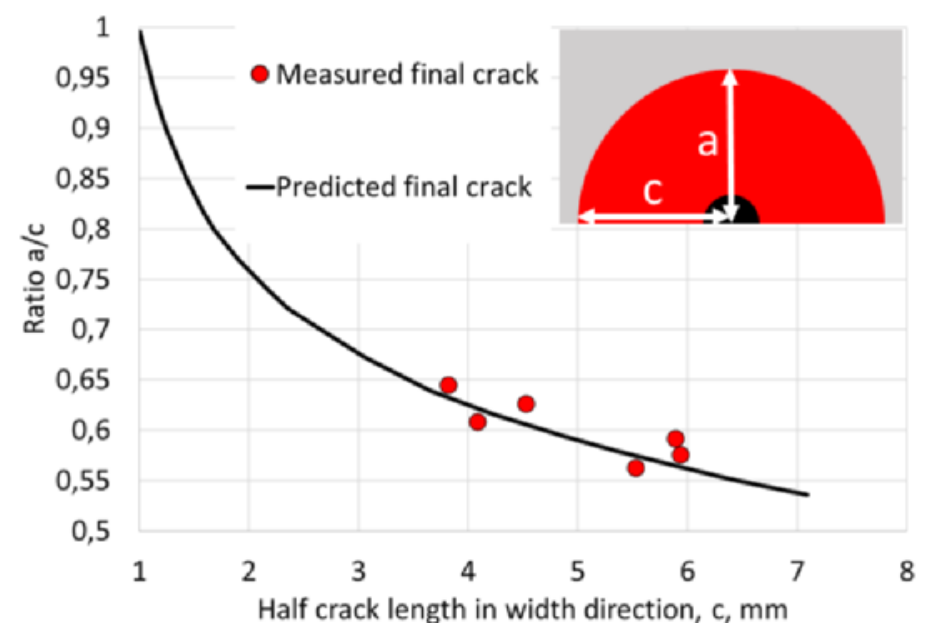

Figure 18. Crack aspect ratio, $a / c$. $a=c r a c k$ length on depth direction, $c=c r a c k$ half-length in width direction. 


\section{Results and Discussion}

Fatigue is often the limiting material property when it comes to dimensioning of structural aerospace parts. There are therefore many fatigue related aspects, illustrated by Figure 19, to be addressed before additively manufactured parts can be introduced to highly loaded aerospace applications. The surface roughness is the most severe factor for fatigue strength of additively manufactured Ti6Al4V and the effect of the roughness and how the fatigue strength can be improved by post processing are presented in section 5.1. Most aerospace parts, however, have geometries with corners or radii that act as stress concentrations and the effect on fatigue strength of notched specimens with and without as-built surface is presented in section 5.2.1.

A modern fighter jet is designed to be in service for 30-40 years [57] during which the aircraft is inspected regularly. Critical parts are often designed with a safety-by-inspection approach which means that inspection intervals and part design are adjusted to ensure that no crack can propagate to a critical size between the inspections. This requires a good knowledge about the FCG behaviour; the effect of geometry and build direction on FCG rates are presented in section 5.2.2. Moreover, aircraft parts are seldom subjected to alternating loads with constant amplitude during flight. Instead, the parts are subjected to variable amplitude loads that depend on part location and type of manoeuvre. The effect of variable amplitude loading and fatigue life predictions are presented in section 5.3.

These areas are discussed in the following sections using the main results from the appended papers. For more test results and details, please refer to appended Paper I- $V$.

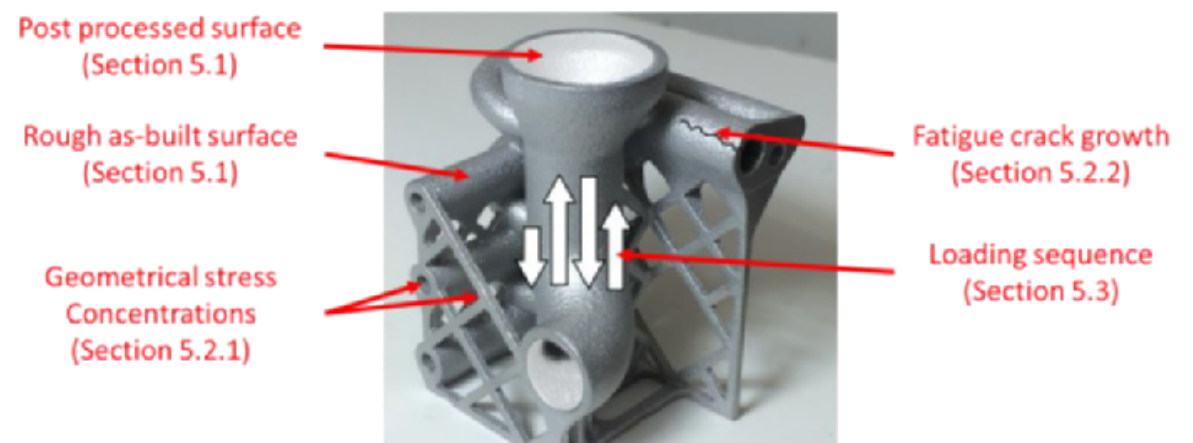

Figure 19. Fatigue related aspects for a highly loaded aerospace AM part. 


\subsection{Effect of Surface Roughness and Residual Stress}

The fatigue limits of E-PBF and L-PBF Ti6A14V are reduced with up to $75 \%$, which are illustrated in Figure 20, due to the rough as-built surface which acts as stress raiser and promotes crack initiations. The results from Paper I are compared to a simultaneous study by Greitemeier et al. [32] and it is evident that the HIP heat treatment, which closes internal LOF:s or pores, increases the fatigue strength of machined samples. However, the HIP treatment has no effect on the fatigue strength for specimens with rough as-built surface since the main "material defect", i.e. the rough surface, still remains when the internal flaws are closed.
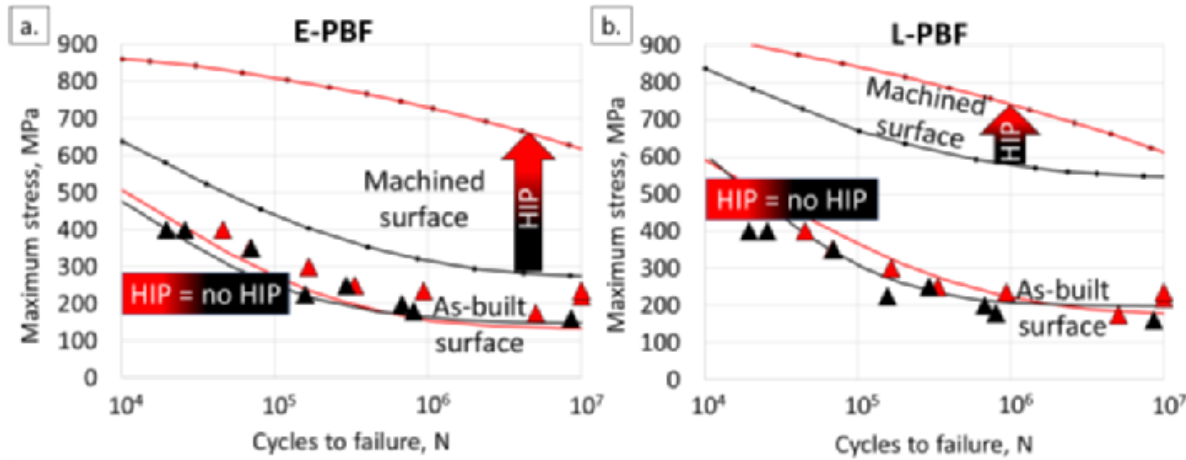

Figure 20. Fatigue life for samples with machined compared to as-built surface. HIP:ed samples are shown as red dots/lines and un-HIPed samples as black dots/lines. a.) E-PBF material, b.) L-PBF material. Data from Paper I (triangles) and Greitemeier et al. [32] (lines).

The surfaces of an additively manufactured part can of course be machined but the geometries will then be restricted to conventional machined features and the main benefit of AM, the freedom of design, would be lost. The amount of machining should therefore be kept to a minimum and other surface post processes that can handle more complex geometries should be used. The surfaces topography of samples subjected to five different surface post processes are shown in Figure 21 and it is evident that E-PBF generally has a rougher surface even after post processing compared to L-PBF material. 


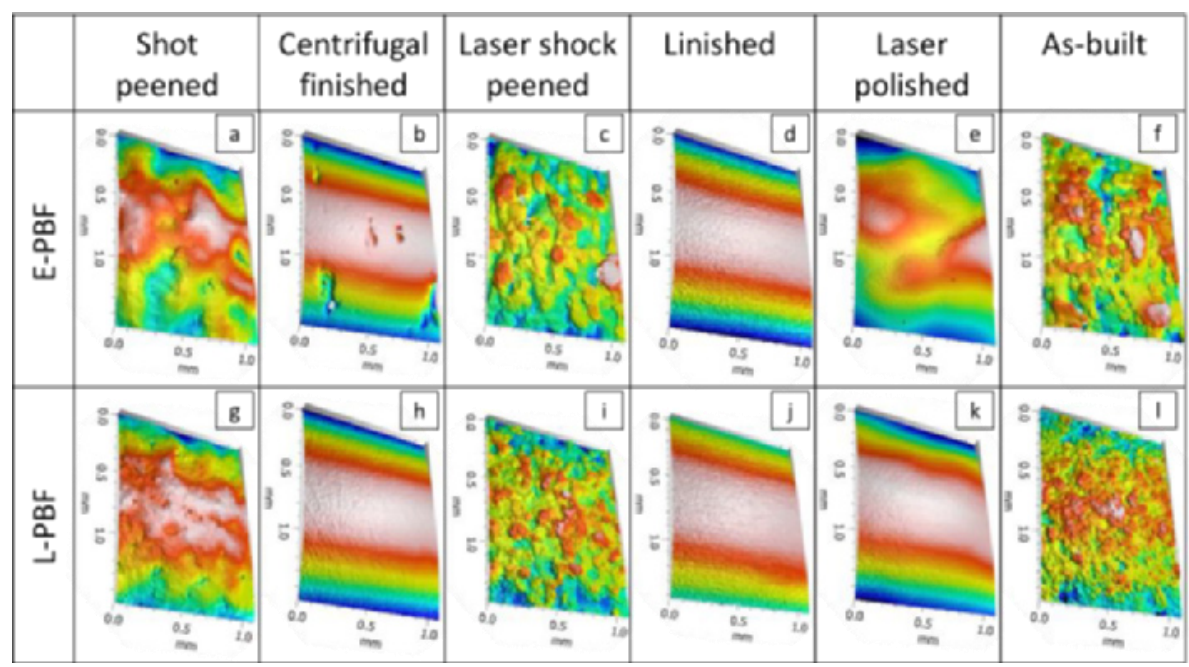

Figure 21. Surface topography of as-built and surface post processed specimens. This image is reused and adapted from $\underline{\text { Paper III }}$ with kind permission of Elsevier.

The differences between post processed E-PBF and L-PBF material are further illustrated in Figure 22 where there is a clear trend of increased fatigue limit with reduced surface roughness. The rougher as-built surface of E-PBF is a disadvantage during post processing as more material need to be removed to achieve a smooth surface. A smooth surface does not, however, guarantee a high fatigue strength; the samples that were laser polished, for example, formed a brittle microstructure after the re-melting of the surface and had very low fatigue strength even though a very fine surface.

L-PBF material subjected to centrifugal finishing or shot peening stand out with higher strength than the linear "surface roughness trend". These specimens had considerable compressive stresses in the surface, see Figure 23, which are beneficial for fatigue strength. Residual stresses act in the same way as fatigue mean stresses and a compressive residual stress would therefore lower the tensile mean stress and increase the fatigue strength at a given number of fatigue load cycles [58]. E-PBF specimens that were subjected to centrifugal finishing or shot peening had similar residual stress at the surface but no apparent increase in fatigue strength compared to the linear roughness trend. This indicates that even small remaining valleys in the surface can reduce the fatigue strength considerably by promoting crack initiations. This is illustrated by the difference 
in topography after centrifugal finishing in Figure $21 \mathrm{~b}$ and Figure $21 \mathrm{~h}$ compared to the differences in the corresponding fatigue limit presented in Figure 22.

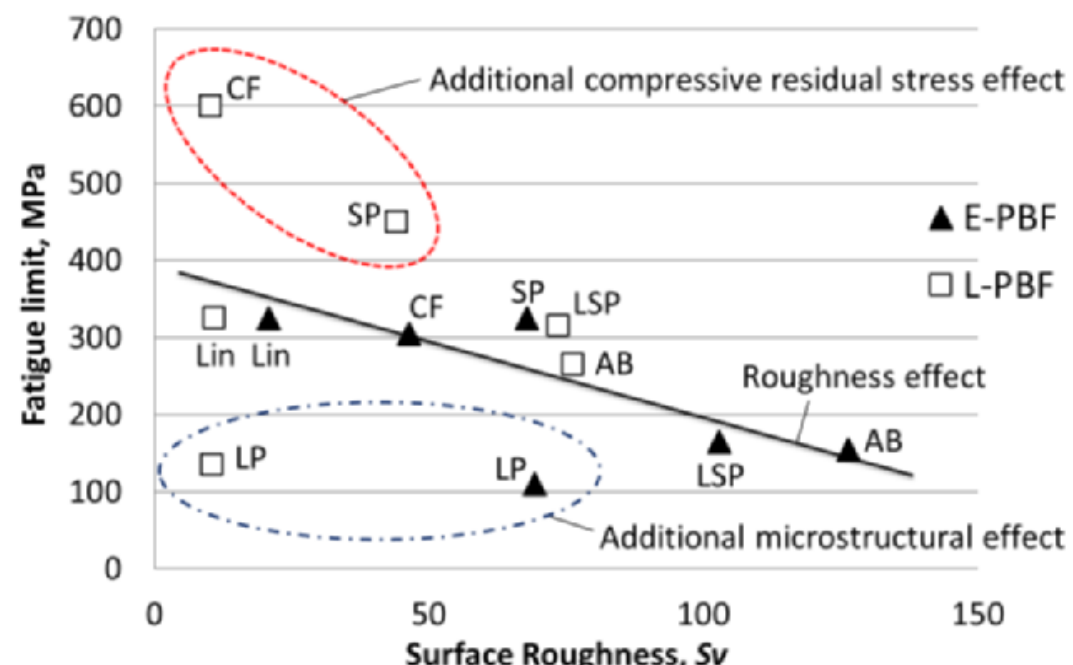

Figure 22. Effect of surface roughness on the fatigue limit at $5 \times 10^{6}$ cycles. $\mathrm{CF}=$ centrifugal finishing, $\mathrm{LSP}=$ laser shock peening, $\mathrm{SP}=$ shot peening, $\mathrm{Lin}=$ linishing, $\mathrm{LP}=$ laser polishing, $\mathrm{AB}=$ as-built, $S v=$ maximum surface valley depth. This image is

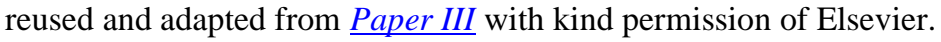

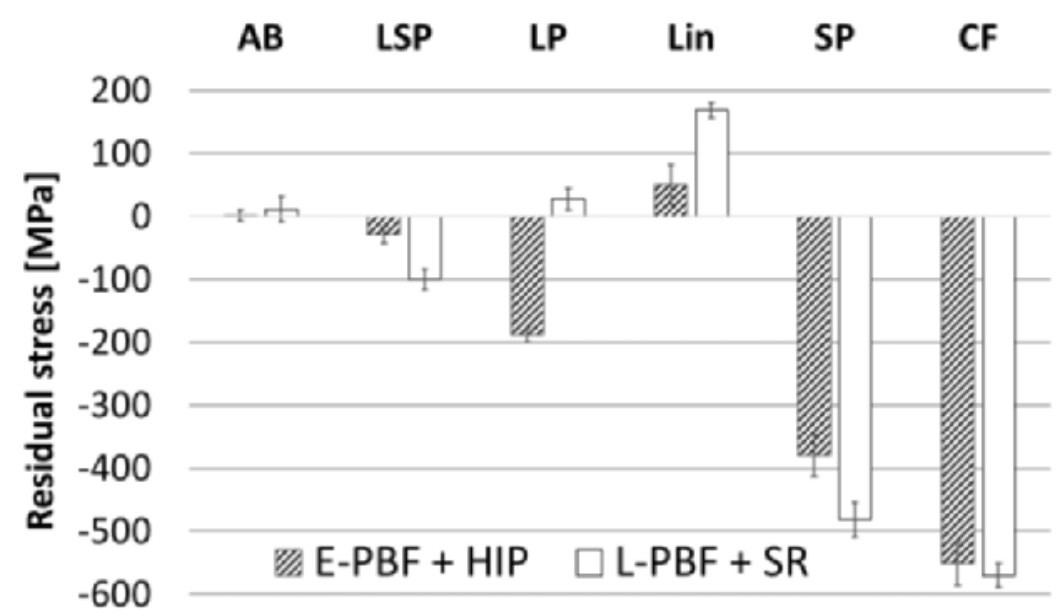

Figure 23. Surface residual stress for as-built and post processed surfaces. This image is reused from $\underline{\text { Paper III }}$ with kind permission of Elsevier. 
It should be noted, that there are other surface post processes than the ones presented in this thesis and that it is possible to combine several post processes in order to further increase the fatigue strength even though this will increase the cost of the final part. The fatigue limits from Paper I and III are compared to previous studies of E-PBF, L-PBF and conventionally wrought Ti6Al4V in Figure 24 and it can be seen that the fatigue limits of E-PBF and L-PBF material with as-built surface are far below that of wrought material. However, similar fatigue limit to wrought material can be achieved for L-PBF material after surface post processing with either shot peening, centrifugal/tumble/vibratory finishing, polishing, micromachining and machining. For E-PBF, however, only specimens that were machined in combination with HIP heat treatment reached similar levels of fatigue strength as wrought Ti6Al4V. There are, however, ongoing studies with Hirtisation surface treatment that show promising results also for E-PBF Ti6Al4V.

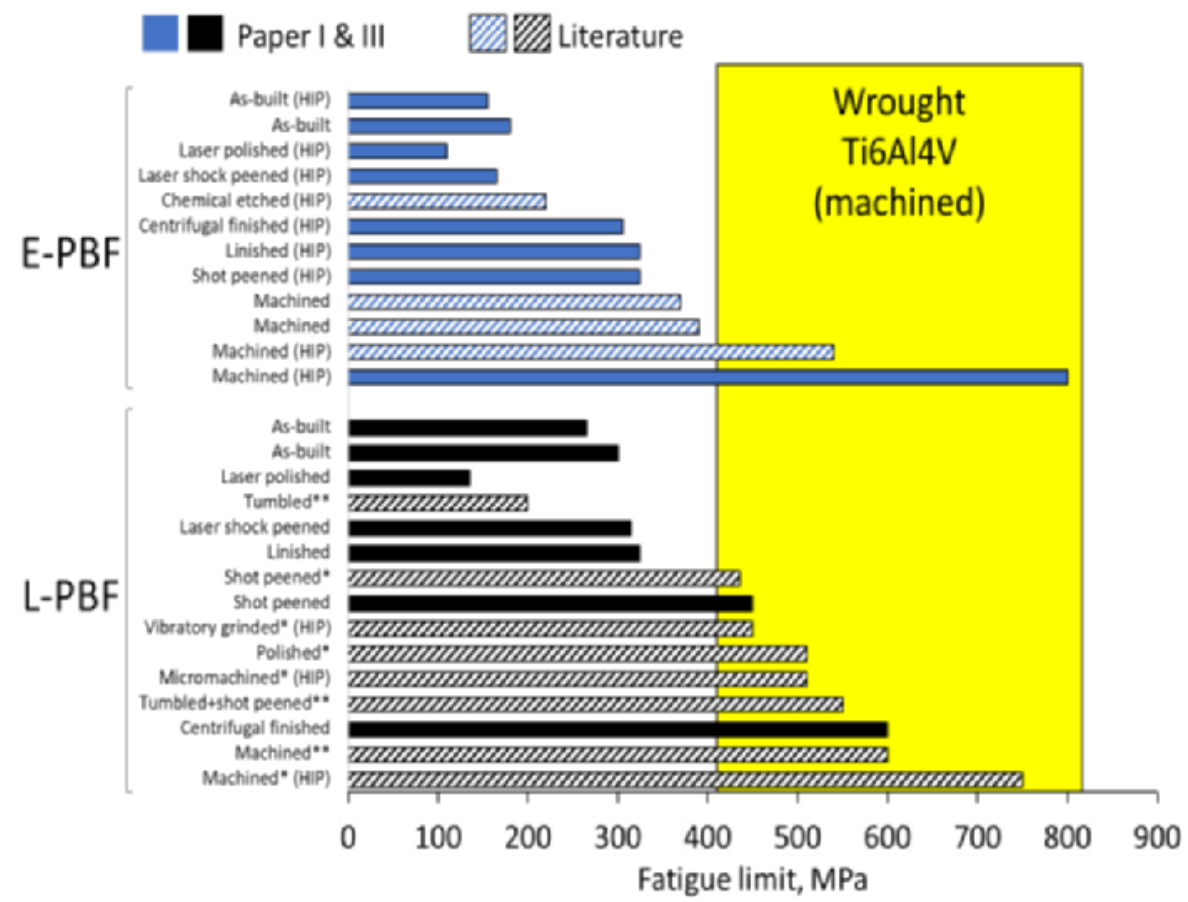

Figure 24. Fatigue limit, at $5 \times 10^{6}$ cycles, for post processed L-PBF and E-PBF Ti6Al4V, loaded in the build direction with $\mathrm{R}=0.1$, compared to wrought Ti6Al4V. Each bar represents result from one study. $* 45^{\circ}$-direction, $* * \mathrm{R}=0$. Data sources [37,59-62].

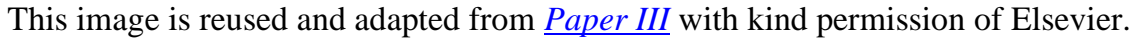




\subsection{Geometrical Effect}

\subsubsection{Stress Concentrations}

A stress concentration is a location where the geometry changes abruptly which will result in a change of the stress flow and a locally higher stress that is increased by a factor called the stress concentration factor, $\mathrm{K}_{\mathrm{t}}$, see Eq. 2:

$$
K_{t}=\frac{\text { maximum stress }}{\text { nominal stress }}
$$

The rough as-built surface, which was discussed in the previous section, will therefore act as a stress concentration. This surface effect will add additional stress concentrations to the effect from any geometrical features on the AM part, such as radii, corners or holes, see examples in Figure 25a. It is therefore of utmost importance to understand the effect on fatigue life not only due to the as-built surface and geometry but also the combination of these two factors. A notch with as-built surface compared to a machined notch are presented in Figure 25b-c.
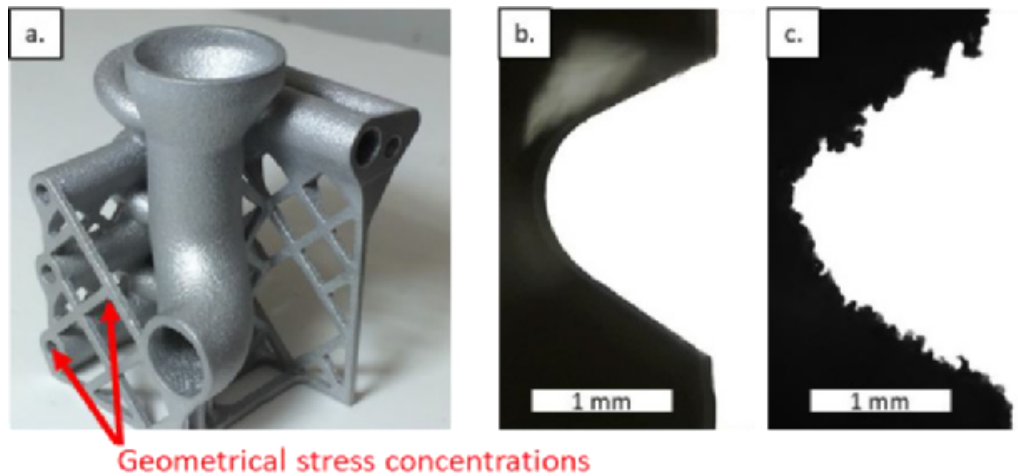

Figure 25. a.) Complex AM geometry with sharp corners, b.) Machined notch, c.) additive manufactured notch (E-PBF).

The reduction of the fatigue limit due to stress concentration is, however, material dependent and it is called the fatigue notch factor, $\mathrm{K}_{\mathrm{f}}$, defined according to Eq. 3 [63]:

$K_{f}=\frac{\text { un-notched fatigue limit }}{\text { notched fatigue limit }}$ 
The fatigue notch factors, $\mathrm{K}_{\mathrm{f}}$, for notched $\mathrm{K}_{\mathrm{t}}=2.5$ specimens with either machined or as-built surface have been determined at $1 \times 10^{6}$ cycles which is illustrated in Figure 26. If only the effect of notch geometry is considered, $\mathrm{K}_{\mathrm{f}}$ is between 1.4-2.2 for L-PBF and E-PBF specimens with as-built surface and between 1.2-1.7 for specimens with machined surface. This is in the same range as for machined wrought material with $\mathrm{K}_{\mathrm{f}}=1.6$ and the effect of "macro-geometry" can be therefore be considered to be similar independent of manufacturing method. However, the combined fatigue notch factor, including both a geometrical macro-notch and micronotches created by the surface roughness, is considerably higher with a $\mathrm{K}_{\mathrm{f}}=4.3$ for $\mathrm{L}-\mathrm{PBF}$ material and $\mathrm{K}_{\mathrm{f}}=6.1$ for E-PBF material. This highlights the importance of consider both the effect of surface and geometry for fatigue life analysis.

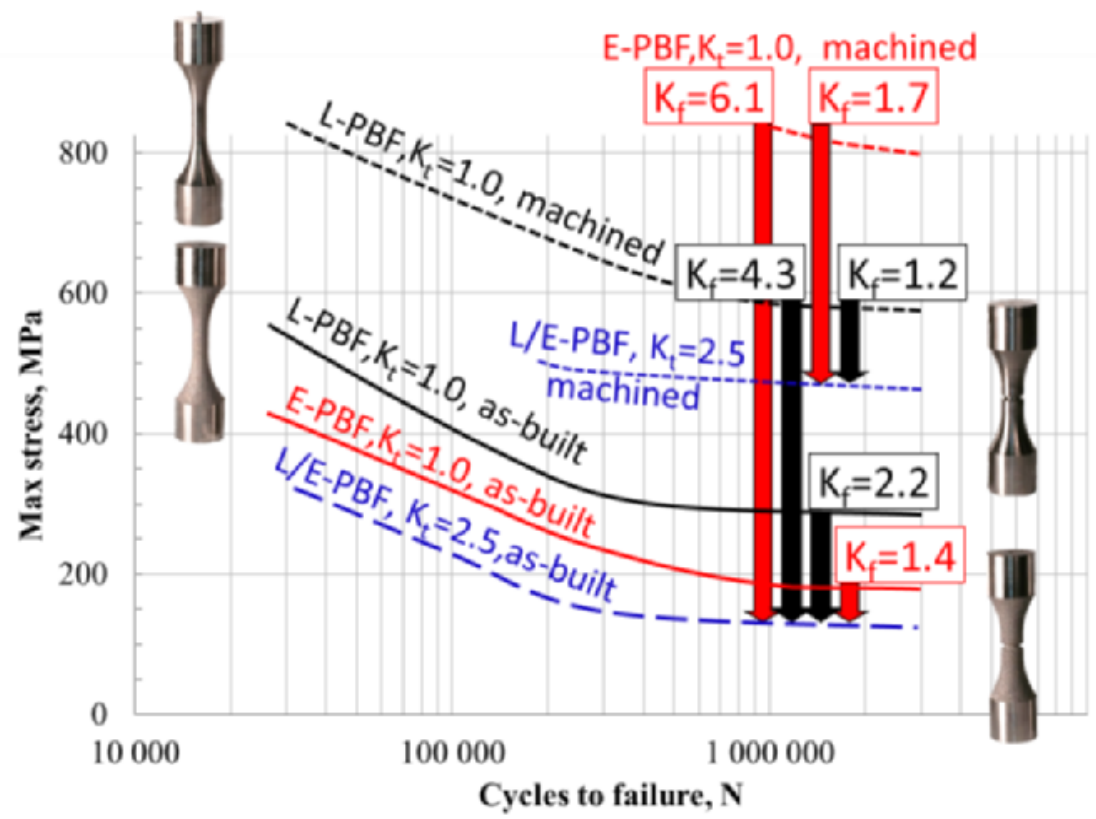

Figure 26. Comparison, at $1 \times 10^{6}$ cycles, of fatigue notch factor $\left(\mathrm{K}_{\mathrm{f}}\right)$ between L-PBF and E-PBF Ti6Al4V with machined and as-built surface. All samples are HIP:ed. Data from Paper $I$.

L-PBF specimens with as-built surface are also compared, in Figure 27, to one of the few parallel fatigue studies, by Nicoletto et al. [64], that have been made on notched additively manufactured specimens. The results correspond well with an increased fatigue notch factor, $\mathrm{K}_{\mathrm{f}}$, with an overall 
increasing stress concentration factor, $\mathrm{K}_{\mathrm{t}}$. What is notable, however, is that the difference in fatigue strength, hence also in $\mathrm{K}_{\mathrm{f}}$, between $\mathrm{K}_{\mathrm{t}}=2.5$ and $\mathrm{K}_{\mathrm{t}}=4.95$ specimens is quite small even though the stress concentration is almost the double. This could partly be explained by differences in test methods, 4-point bending with $\mathrm{R}=0$ compared to axial tests with $\mathrm{R}=0.1$, which can give different stress gradients. However, one should be aware that both AM and machining can result in shapes and dimensions deviating from the original CAD-model, see Figure 25b-c, and thereby give a different stress concentration than expected. It is therefore necessary to control the dimensions after manufacturing. The notched specimens from the studies in Paper I-II were therefore measured and re-modelled using FE-modelling. The modelling showed a stress concentration of $\mathrm{K}_{\mathrm{t}}=2.47$ and $\mathrm{K}_{\mathrm{t}}=2.37$ for the machined and the additively manufactured notches respectively which are considered comparable to the intended $\mathrm{K}_{\mathrm{t}}=2.5$.

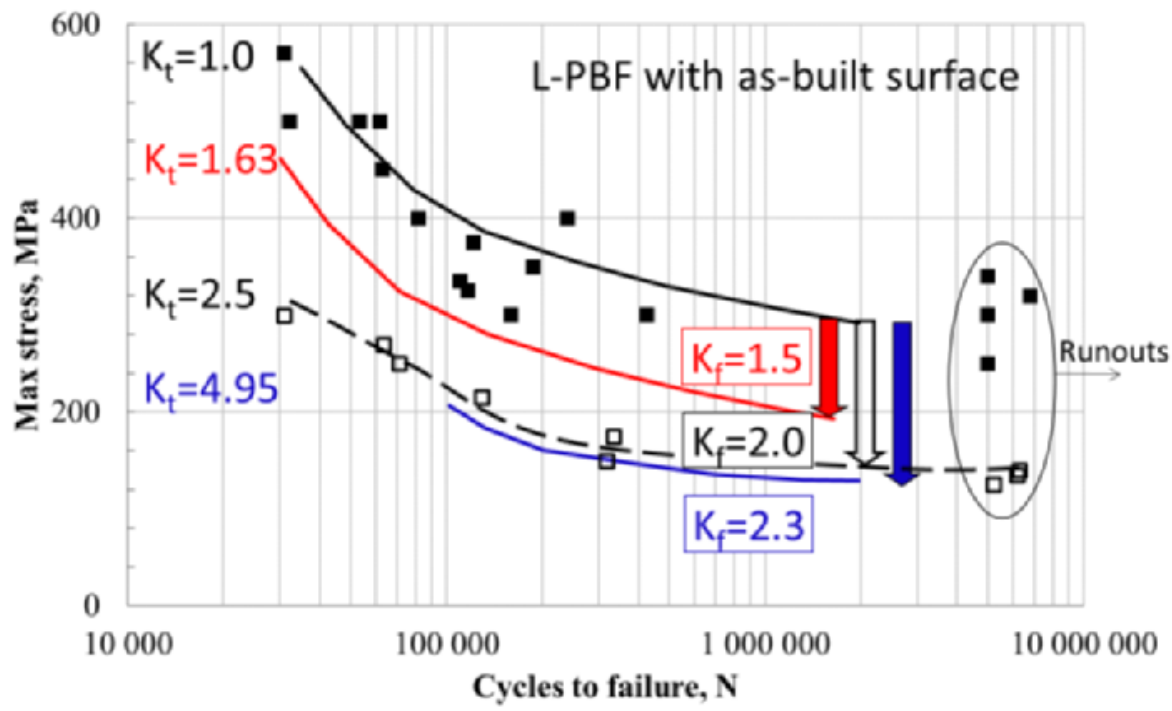

Figure 27. Fatigue notch factor for L-PBF specimens with as-built surface. Results from Paper I (dots and dashed line) with $\mathrm{R}=0.1$ compared to C-types specimen from Nicoletto et al. [64] (solid lines) with $\mathrm{R}=0$. 


\subsubsection{FCG with Through or Part-through Cracks}

The aerospace industry often uses a safety-by-inspection methodology to ensure airworthiness of the aircraft. This requires that the FCG relation to the stress intensity factor range, $\Delta \mathrm{K}$, is applicable independent of geometry and stress, i.e. the concept of similitude. This concept was first suggested by Paris et al. [65] in 1961 and Paris and Erdogan [66] in 1963 which led to the well know Paris equation. Standard CT specimens are often used to produce material data that are fitted to the Paris equation. However, CT specimens have a geometry that force the crack to growth through the entire specimen thickness, i.e. there is only crack growth in one direction. A crack in a real aerospace part most often starts from a point defect in, for example, a radius and thereafter grow in both the depth and the width direction simultaneously as illustrated by Figure $16 \mathrm{~b}$.

However, the results presented in Figure 28 show that the through cracks of CT-specimens, in L-PBF Ti6Al4V material, have the same FCG rate as the part-through cracks of keyhole specimens when the stress intensity factor range is the same. This confirms that the similitude concept applies, at least for cracks that are of sizes relevant for evaluations of aerospace applications, i.e. $1 \mathrm{~mm}$ and larger.

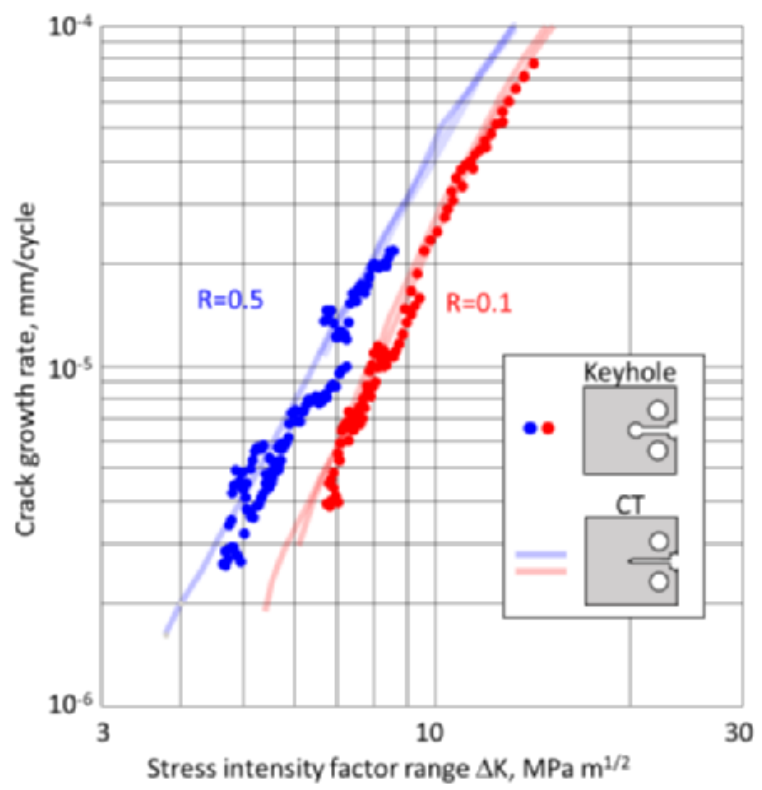

Figure 28. Comparison between FCG rates for through cracks (CT) and part-through cracks (keyhole). This image is reused from Paper $V$ with kind permission of Elsevier. 
Moreover, the FCG rates from Paper $V$ are compared to five previous studies of heat treated L-PBF Ti6Al4V and the FCG rates for cracks propagating parallel and perpendicular to the AM build direction are quite similar as illustrated by Figure 29. There is only minor anisotropy between the material directions and the scatter between different builds and powder batches are at least as large as any anisotropy found within a single study. From an industrial point of view, the FCG rate should therefore not be regarded as anisotropic within the Paris law region and one should instead consider the overall scatter which more or less covers the same ranges as for conventional wrought Ti6Al4V material as seen in Figure 29.

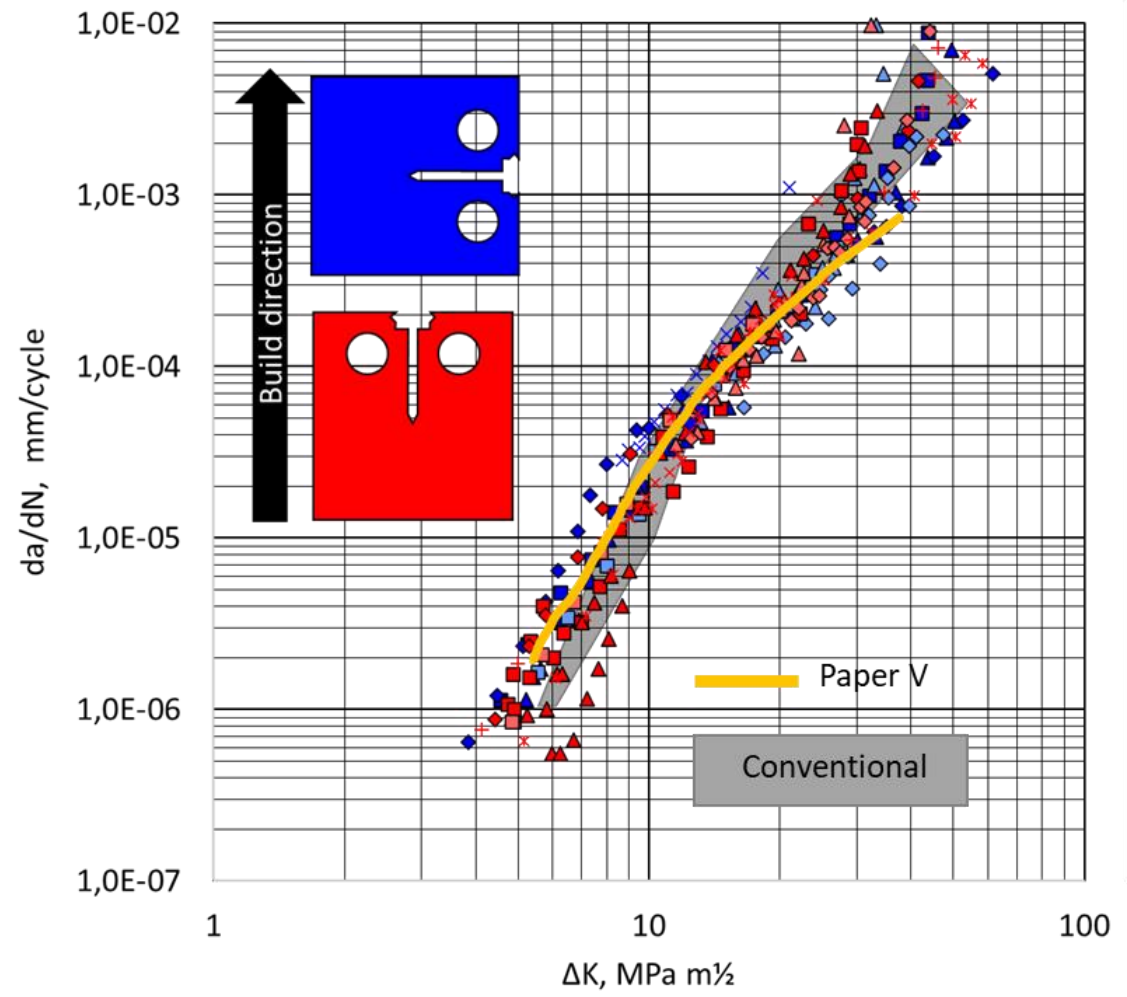

Figure 29. FCG rates for $\mathrm{R}=0.1$ for heat treated Ti6Al4V with crack propagation parallel (red) and perpendicular (blue) to the AM build direction. Data from [32,67-73]. This image is reused from Paper $V$ with kind permission of Elsevier. 


\subsection{Loading Effect}

More or less all fatigue tests, in literature, are performed with constant amplitude load, or constant amplitude strain for strain-controlled tests. However, most structural aerospace parts are subjected to variable amplitude loading during flight [74] which could give different material response dependent on which order the loads are applied and due to local plastic deformation after high peak loads [75]. For new materials, like additively manufactured materials, it is therefore necessary to confirm that there are no un-expected effects due to variable amplitude loading compared to the investigations with constant amplitude loading.

The fatigue life of E-PBF and L-PBF Ti6A14V with either as-built or post processed surface were investigated with variable amplitude loading using the Short-FALSTAFF load sequence. The fatigue response is presented in Figure 30 and similar relations between as-built and surface post processed conditions compared to constant amplitude loading, presented in Figure 24, can be seen; L-PBF material subjected to centrifugal finishing showed the longest fatigue life followed by L-PBF subjected to shot peening.

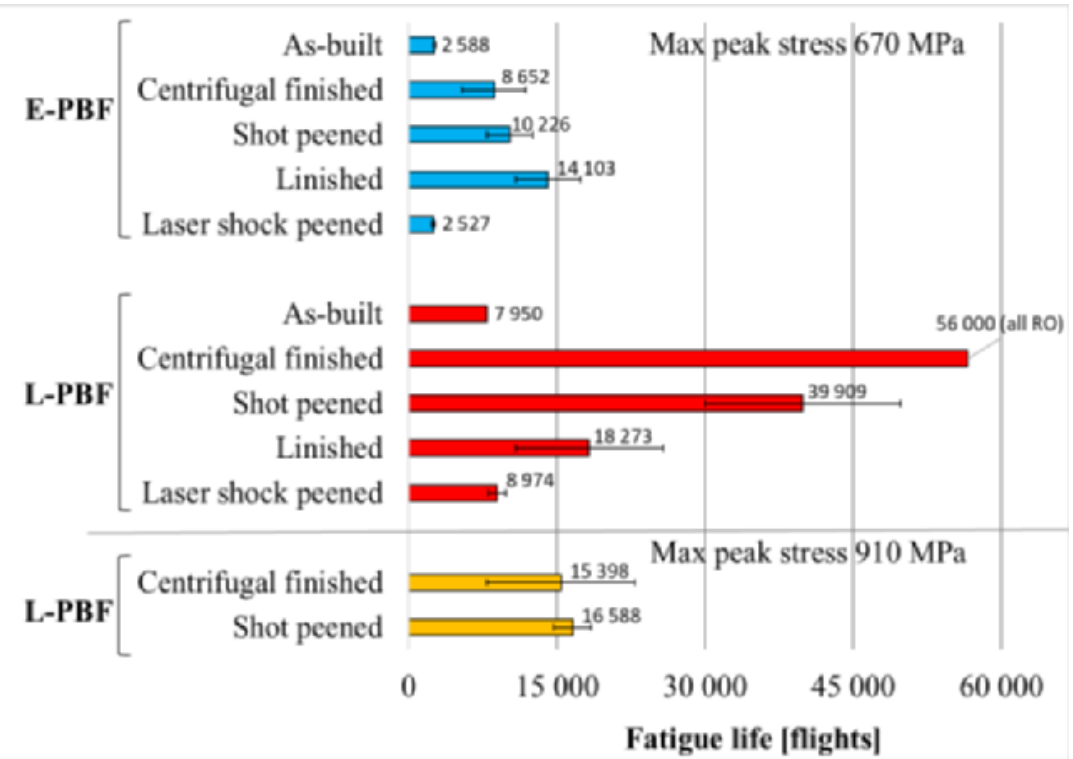

Figure 30. Average fatigue life for variable amplitude loaded. Error bars indicate standard deviation. $\mathrm{RO}=$ runout. This image is reused from $\underline{\text { Paper } I V}$ with kind permission of Elsevier. 
However, for variable amplitude loading with a higher maximum load (910 MPa), which is closer to the material yield strength (1049 MPa) for this build, the fatigue life is similar for centrifugal finished and shot peened L-PBF material as illustrated in Figure 30. This means that one cannot conclude that centrifugal finishing always has a higher fatigue strength compared to shot peening which otherwise would be the conclusion from both the constant amplitude testing and the variable amplitude testing at the lower maximum stress (670 MPa).

Fatigue design data in handbooks are generally based on constant amplitude fatigue data. In order to use this data for fatigue life calculations of real aerospace parts subjected to variable amplitude loading one can use, for example, the common cumulative damage approach in which the load sequence, presented in Figure 12, is divided into rain-flow counted constant amplitude cycles, illustrated by Figure 15. The fatigue damage caused by each cycle is then calculated with constant amplitude fatigue design data using, for example, the Palmgren-Minor's linear damage rule $[37,38]$ after which the resulting variable amplitude fatigue life could be predicted.

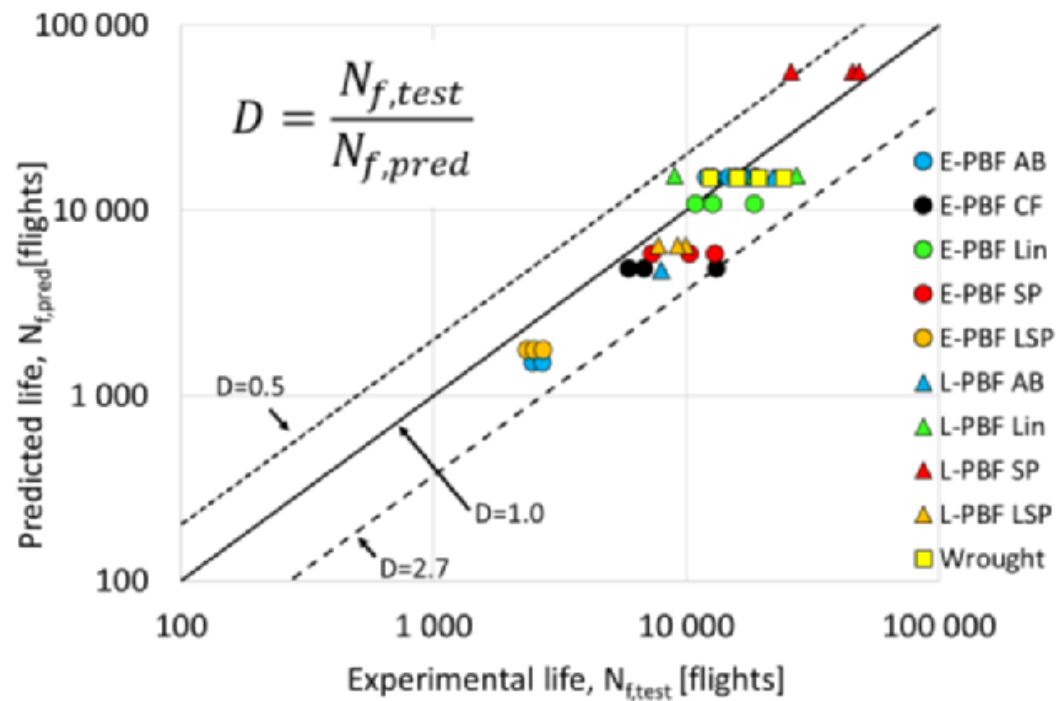

Figure 31. Experimental life compared to predictions. $\mathrm{AB}=$ as-built, $\mathrm{CF}=$ centrifugal finishing, Lin=linishing, $\mathrm{SP}=$ shot peening, $\mathrm{LSP}=$ laser shock peening. Data from Paper $I I \& I V$. 
A comparison between the predicted fatigue life and the fatigue life from tests with variable amplitude loading is presented in Figure 31 for both un-notched and notched specimens with as-built surface and for unnotched specimens subjected to surface post processing. The life ratio, D, between experimental life and predicted life is between $0.5 \leq \mathrm{D} \leq 2.7$ with most tests located slightly above $\mathrm{D}=1$, i.e. with an experimental life slightly longer than the predicted life. This is a relatively small scatter and the wrought Ti6Al4V, presented in Figure 31, show a similar scatter in life ratio.

The available literature is very limited for variable amplitude fatigue since most investigations are performed in-house by end-user companies. The appended Paper II was the first published journal paper, to the author's knowledge, on variable amplitude fatigue for additively manufactured materials. Apart from Paper IV, there have been only one subsequent journal paper on variable amplitude loading for AM metals [76]. The average life ratio, D, from the tensile dominated load sequence from that study of additively manufactured steel corresponds, however, well with the life ratios, D, from Paper II and IV which further indicates that cumulative damage is a relevant approach to predict the fatigue life for additively manufactured materials. 


\section{Summary of Appended Papers}

\section{Paper I}

Fatigue behaviour of notched additive manufactured Ti6Al4V with asbuilt surfaces

Few aerospace parts have simple flat geometries, instead fatigue cracks start from corners or radii that act as stress concentrations which motivates this study of notched L-PBF and E-PBF additively manufactured Ti6Al4V specimens. The effect on fatigue due to the rough as-built surface and the combined effect of macro-geometrical notches, built directly by AM, and micro-notches caused by the rough as-built surface were determined. It was found that the rough as-built surface was the single worst factor for fatigue resulting in a reduction of the fatigue strength of up to $75 \%$. The combined effect of geometrical notches and as-built surface resulted, however, in even larger reductions which need to be considered when designing aerospace parts for AM. Furthermore, it was found that HIP did not improve the fatigue strength for specimens with as-built surface since the rough as-built surface was more detrimental than any internal defects that could be closed by HIP.

\section{Paper II}

Fatigue behaviour of additive manufactured Ti6Al4V, with as-built surfaces, exposed to variable amplitude loading

As a continuation to the work described in Paper I, notched and unnotched specimens were further tested using the variable amplitude load spectrum Short-FALSTAFF to investigate if the fatigue response was consistent to the behaviour for constant amplitude loading. The variable amplitude fatigue life was tested with a maximum net section peak stress that was predicted, using constant amplitude fatigue data and a cumulative damage approach, to give a fatigue life of 15000 flights. The experimental and the predicted fatigue life were overall very consistent with a ratio between experimental and predicted life between 0.8-1.6, for notched and un-notched specimens, which was the same interval also 
found for wrought Ti6Al4V material. This shows that a cumulative damage approach can be used to give reliable fatigue life predictions for additively manufactured Ti6Al4V parts with rough as-built surface subjected to variable amplitude loading.

\section{Paper III}

Improved fatigue strength of additively manufactured Ti6Al4V by surface post processing

The low fatigue strength of L-PBF and E-PBF Ti6Al4V associated to the rough as-built surface can be improved through surface post processing by smoothening of the surface and/or introducing compressive residual stresses. Milling is an option but can only produce conventionally milled geometries and the inherent benefit of freedom of design for additively manufactured parts would be lost. Five surface post processes that can handle different degree of complex geometries were therefore investigated in this study. The post processes investigated were shot peening, centrifugal finishing, laser shock, peening, linishing and laser polishing. It was found that a smoother surface generally gives improved fatigue strength but a smooth surface is, however, not a guarantee for high fatigue strength since surface residual stress, microstructure and remaining subsurface defects also affect the fatigue strength. Shot peening and centrifugal finishing introduced high compressive residual stresses at the surface which generally are beneficial for fatigue strength. The fatigue limits of L-PBF specimens subjected to shot peening or centrifugal finishing were improved to levels comparable to conventional wrought Ti6Al4V. The corresponding E-PBF specimens were improved with over $100 \%$ but were still inferior to the fatigue limit of wrought material. This lower fatigue limit was attributed to large remaining surface defects that were either hidden below the surface or too large be to be removed by the post processing. 


\section{Paper IV}

Variable amplitude loading of additively manufactured Ti6Al4V subjected to surface post processes

The top four post processes from Paper III were further investigated in this study using the variable amplitude load spectrum Short-FALSTAFF. Variable amplitude loading can give a different material response, compared to constant amplitude loading, due to effects of load sequence order and associated local plastic deformations. Additively manufactured materials have, furthermore, a complex stress situation at the surface with residual stress, rough as-built surface or hidden defects below the surface acting as stress concentrations and it is therefore of great importance to verify that the impact of these aspects could be included in fatigue life predictions. The fatigue life for variable amplitude loading was predicted with a cumulative damage approach using constant amplitude fatigue data. The predictions were compared to test results for two different levels of maximum net section peak stress, 670 and $910 \mathrm{MPa}$. Similar relationships between the fatigue life of post processed specimens as for constant amplitude loading were found for the $670 \mathrm{MPa}$ load level with the longest fatigue life for L-PBF Ti6Al4V material subjected to centrifugal finishing. At the higher load level, however, centrifugal finishing had similar fatigue life to L-PBF material subjected to shot peening which indicates that loading can influence the material behaviour. The fatigue life of post processed E-PBF Ti6Al4V material was improved with more than five times, compared to as-built condition, by linishing but had still inferior strength compared to post processed L-PBF material. This was attributed to the inherent rougher surface of the E-PBF material which was difficult to completely remove with post processing. The fatigue life was however predicted with good accuracy, for all post processes for both E-PBF and L-PBF material, using the cumulative damage approach. 


\section{Paper V}

Fatigue Crack Growth for Through and Part-through Cracks in Additively Manufactured Ti6Al4V

FCG behaviour of additively manufactured materials needs to be well known if critical aircraft parts are going to be produced by AM since it affects the service intervals of the aircraft. In this study, the FCG behaviour of heat treated L-PBF Ti6A14V was investigated. The FCG rates for a standard CT-specimen with a sharp notch and through going crack were compared to a keyhole specimen in which the crack starts to propagate from a surface defect within a large radius. In the latter, the crack grows within the thickness of the specimen and the test was stopped before the crack reached the outer surface. The FCG growth in a keyhole specimen represents, therefore, the behaviour in a real aircraft part with thick walls more accurate than a CT-specimen. The crack growth in the hidden direction for the keyhole specimens was determined by FE-modelling of the advancing crack in the specimen using the displacement and load input from the testing. The final crack lengths of the part-through cracks in the keyhole specimens had good agreement with the predictions. Furthermore, the FCG rates of CT and keyhole specimens were found to be very similar which indicate that the concept of similitude applies, at least for cracks that are of sizes that are relevant from an industrial perspective. FCG rates from CT specimens can therefore be considered relevant for general crack growth predictions even for parts with part-through cracking. 


\section{Conclusions}

In aerospace, additive manufacturing has great potential to reduce the weight of aerospace parts and improve the performance of aerospace systems which both could contribute to reduced emissions. The focus in this $\mathrm{PhD}$ project has been to investigate the fatigue and damage tolerance behaviour of additively manufactured Ti6Al4V to obtain sufficient confidence and knowledge to allow additive manufacturing of high-performance aerospace parts and systems.

By the work performed within this project, together with several parallel studies, the previous lack of knowledge about fatigue behaviour is no longer a major obstacle for the introduction of laser powder bed fusion (L-PBF) and electron beam powder bed fusion (E-PBF) Ti6Al4V material to highly loaded aerospace applications. There is now, for example, enough information to produce complete design data for fatigue life analysis that includes the effect of surface roughness, geometrical notches, heat treatment, material direction and material thickness.

The main conclusions drawn from the scope of this thesis are:

- The rough surface for parts with as-built surface is the single worst factor for fatigue resulting in a reduction of fatigue strength with up to $75 \%$. Hot isostatic pressing (HIP) has therefore negligible effect on fatigue since the as-built surface is more severe than any internal defects.

- Surface post processing can improve the fatigue strength of L-PBF material to levels comparable to conventional wrought material. Only machining in combination with HIP has, to date, been able to improve the fatigue strength of E-PBF material to similar levels due to the inherent rougher surface of E-PBF material.

- The surface roughness alone is, however, an insufficient indicator of the fatigue strength since the final fatigue strength can be lowered by subsurface defects and brittle microstructure and increased by compressive surface residual stresses. 
- The combined effects of surface roughness and geometrical notches are needed to predict the correct fatigue response; the fatigue notch factors $\left(\mathrm{K}_{\mathrm{f}}\right)$ of 6.1 and 4.3 were found between machined smooth samples and notched $\left(\mathrm{K}_{\mathrm{t}}=2.5\right)$ samples with asbuilt surface for L-PBF and E-PBF material respectively. This is considerably higher than the corresponding $\mathrm{K}_{\mathrm{f}}=1.6$ for wrought material.

- Variable amplitude loading does not affect the fatigue life in any unexpected way and the fatigue life can therefore be predicted with a conventional cumulative damage approach using data from constant amplitude tests.

- The fatigue crack growth (FCG) rates for heat treated L-PBF material are similar to rates for conventional Ti6Al4V. The rates are independent of crack geometry and load condition, which mean that the concept of similitude applies at least for cracks of sizes that are relevant from an engineering perspective. Conventional damage tolerance analysis based on linear elastic fracture mechanics seem therefore appropriate to use.

From these conclusions, one can see that the fatigue behaviour for additively manufactured Ti6Al4V can be very different compared to conventional wrought material, but the material response is predictable and can be analysed and estimated using the same methods as for conventional materials. Results from the work presented in this thesis have already contributed to the dimensioning of non-critical aircraft parts, subjected to low loads, that now are in serial production. 


\section{Outlook}

Even though the material behaviour now is quite well understood, there is to date still a lack of applicable methods and standards for non-destructive testing (NDT) of additively manufactured metals which now is the next show-stopper for introducing additively manufactured metals to critical aerospace applications. The focus of upcoming research applications should therefore be within quality assurance, in-process control and NDT to overcome these major obstacles, to date, for a full industrialization of AM.

Even if NDT now is the bottle-neck for introduction of AM, there are still material related aspects that require further activities to enable the full potential of additively manufactured materials to be used:

- The same FCG data used for conventional wrought Ti6Al4V can most likely also be used for additively manufactured material but further testing is needed to consolidate this conclusion; variable amplitude load spectrums and additional specimen geometries, e.g. open hole specimens with corner cracks, should be tested and compared to wrought material.

- Post processing is, obviously, very process dependent and further work with improved or additional processes, like Hirtisation, should be performed to find additional cost-efficient post process solutions that can access complex AM geometries.

- Additively manufactured high strength aluminium has gained a lot of interest in the last couple of years and multiple research projects to develop new alloys are currently ongoing. These efforts are very welcome to the aerospace industry, but it will take even larger efforts to characterize all new alloys to levels required for aerospace applications. A tough down-selection of alloys will be required to gather enough knowledge on a selected few alloys rather than scattered efforts across the lot. 


\section{Bibliography}

[1] Andrejiová M, Grincova A, Marasová D. Study of the percentage of greenhouse gas emissions from aviation in the EU-27 countries by applying multiple-criteria statistical methods. Int J Environ Res Public Health 2020; vol.17. doi:10.3390/ijerph17113759.

[2] Huang R, Riddle M, Graziano D, Warren J, Das S, Nimbalkar S, et al. Energy and emissions saving potential of additive manufacturing: the case of lightweight aircraft components. J Clean Prod 2016; vol.135: pp.1559-70. doi:10.1016/j.jclepro.2015.04.109.

[3] Kahlin M. Fatigue Performance of Additive Manufactured Ti6Al4V in Aerospace Applications. Linköping University, 2017. doi:10.3384/lic.diva137233.

[4] Horn TJ, Harrysson OLA. Overview of current additive manufacturing technologies and selected applications. Sci Prog 2012; vol.95: pp.255-82. doi:10.3184/003685012X13420984463047.

[5] Frazier WE. Metal additive manufacturing: A review. J Mater Eng Perform 2014; vol.23: pp.1917-28. doi:10.1007/s11665-014-0958-z.

[6] Manfredi D, Calignano F, Krishnan M, Canali R, Paola E, Biamino S, et al. Additive Manufacturing of Al Alloys and Aluminium Matrix Composites (AMCs). Light Met Alloy Appl 2014: pp.1-23. doi:10.5772/58534.

[7] Boeing, www.boeing.com (accessed March 17, 2021).

[8] Siemens Energy, www.siemens-energy.com (accessed March 17, 2021).

[9] GE Additive, www.ge.com/additive/ (accessed March 15, 2021).

[10] Yusuf SM, Cutler S, Gao N. Review: The impact of metal additive manufacturing on the aerospace industry. Metals (Basel) 2019; vol.9. doi:10.3390/met9121286.

[11] Hällgren S, Pejryd L, Ekengren J. Additive Manufacturing and High Speed Machining -Cost comparison of short lead time manufacturing methods. Procedia CIRP 2016; vol.50: pp.384-9. doi:10.1016/j.procir.2016.05.049.

[12] Jiang J, Xu X, Stringer J. Support Structures for Additive Manufacturing: A Review. J Manuf Mater Process 2018; vol.2:4. doi:10.3390/jmmp2040064.

[13] Arısoy YM, Criales LE, Özel T, Lane B, Moylan S, Donmez A. Influence of scan strategy and process parameters on microstructure and its optimization in additively manufactured nickel alloy 625 via laser powder bed fusion. Int $\mathrm{J}$ Adv Manuf Technol 2017; vol.90: pp.1393-417. doi:10.1007/s00170-016-9429-z.

[14] Léonard F, Tammas-Williams S, Todd I. CT for Additive Manufacturing Process Characterisation: Assessment of melt strategies on defect population. 6th Conf Ind Comput Tomogr,Wels, Austria, 2016. 
[15] Artzt K, Mishurova T, Bauer PP, Gussone J, Barriobero-Vila P, Evsevleev S, et al. Pandora's box-influence of contour parameters on roughness and subsurface residual stresses in laser powder bed fusion of Ti-6Al-4V. Materials 2020; vol.13: pp.1-24. doi:10.3390/ma13153348.

[16] Clijsters S, Craeghs T, Buls S, Kempen K, Kruth JP. In situ quality control of the selective laser melting process using a high-speed, real-time melt pool monitoring system. Int J Adv Manuf Technol 2014; vol.75: pp.1089-101. doi:10.1007/s00170-014-6214-8.

[17] Leicht A, Rashidi M, Klement U, Hryha E. Effect of process parameters on the microstructure, tensile strength and productivity of 316L parts produced by laser powder bed fusion. Mater Charact 2020; vol.159: article 110016. doi:10.1016/j.matchar.2019.110016.

[18] Maimaitiyili T, Mosur K, Kurzynowski T, Casati N, Swygenhoven H Van. Phase studies of additively manufactured near beta titanium alloy-Ti55511. Materials 2020; vol.13. doi:10.3390/ma13071723.

[19] EOS, www.eos.info (accessed March 15, 2021).

[20] SLM Solutions, www.slm-solutions.com (accessed March 15, 2021).

[21] Neikter M, Colliander M, de Andrade Schwerz C, Hansson T, Åkerfeldt P, Pederson R, et al. Fatigue crack growth of electron beam melted Ti-6Al-4V in high-pressure hydrogen. Materials 2020; vol.13. doi:10.3390/ma13061287.

[22] Lewandowski JJ, Seifi M. Metal Additive Manufacturing: A Review of Mechanical Properties. Annu Rev Mater Res 2016; vol.46: pp.151-86. doi:10.1146/annurev-matsci-070115-032024.

[23] Tofail SAM, Koumoulos EP, Bandyopadhyay A, Bose S, O'Donoghue L, Charitidis C. Additive manufacturing: scientific and technological challenges, market uptake and opportunities. Mater Today 2018; vol.21: pp.22-37. doi:10.1016/j.mattod.2017.07.001.

[24] Najmon JC, Raeisi S, Tovar A. Review of additive manufacturing technologies and applications in the aerospace industry. Elsevier Inc.; 2019, pp. 7-31. doi:10.1016/B978-0-12-814062-8.00002-9.

[25] Matthews N. Additive Metal Technologies for Aerospace Sustainment. Elsevier Ltd.; 2018, pp.845-862. doi:10.1016/B978-0-08-100540-8.00015-7.

[26] Uriondo A, Esperon-Miguez M, Perinpanayagam S. The present and future of additive manufacturing in the aerospace sector: A review of important aspects. Proc Inst Mech Eng Part G J Aerosp Eng 2015; vol.229: pp.2132-47. doi: $10.1177 / 0954410014568797$.

[27] Padmanabham G, Shanmugarajan B, Laser-based joining of Metallic and NonMetallic Materials, Laser-Assisted Fabrication of Materials. Springer 2013; pp.159-220. doi:10.1007/978-3-642-28359-8.

[28] Younossi O, Seong S, Goldsmith BW. Titanium Industrial Base, Price Trends, and Technology Initiatives. RAND Corporation, 2009. 
[29] Chan KS, Koike M, Mason RL, Okabe T. Fatigue life of titanium alloys fabricated by additive layer manufacturing techniques for dental implants. Metall Mater Trans A Phys Metall Mater Sci 2013; vol.44: pp.1010-22. doi:10.1007/s11661-012-1470-4.

[30] Rafi HK, Karthik N V., Gong H, Starr TL, Stucker BE. Microstructures and mechanical properties of Ti6Al4V parts fabricated by selective laser melting and electron beam melting. J Mater Eng Perform 2013; vol.22: pp.3872-83. doi:10.1007/s11665-013-0658-0.

[31] Kasperovich G, Hausmann J. Improvement of fatigue resistance and ductility of TiAl6V4 processed by selective laser melting. J Mater Process Technol 2015; vol.220: pp.202-14. doi:10.1016/j.jmatprotec.2015.01.025.

[32] Greitemeier D, Palm F, Syassen F, Melz T. Fatigue performance of additive manufactured TiAl6V4 using electron and laser beam melting. Int $\mathrm{J}$ Fatigue 2017; vol.94: pp.211-7. doi:10.1016/j.ijfatigue.2016.05.001.

[33] Greitemeier D, Holzinger V, Donne CD, Eufinger J, Melz T. Fatigue prediction of additive manufactured Ti-6Al-4V for aerospace : Effect of defects, surface roughness. 28th ICAF Symp - Helsinki 2015, Report-NoTX2-2015-120 2015:3-5.

[34] Algardh JK, Horn T, West H, Aman R, Snis A, Engqvist H, et al. Thickness dependency of mechanical properties for thin-walled titanium parts manufactured by Electron Beam Melting (EBM)®. Addit Manuf 2016; vol.12: pp.45-50. doi:10.1016/j.addma.2016.06.009.

[35] Donachie MJ. Titanium : A Technical Guide. 2nd ed. ASM International; 2000.

[36] Edwards P, O'Conner A, Ramulu M. Electron Beam Additive Manufacturing of Titanium Components: Properties and Performance. J Manuf Sci Eng 2013; vol.135. doi:10.1115/1.4025773.

[37] Svensson M, Ackelid U, Ab A. Titanium Alloys Manufactured with Electron Beam Melting Mechanical and Chemical Properties. Med. Device Mater. V Proc. from Mater. Process. Med. Devices Conf. 2009, pp.189-194. doi:10.1007/978-4-431-54237-7.

[38] Antonysamy AA, Meyer J, Prangnell PB. Effect of build geometry on the $\beta$ grain structure and texture in additive manufacture of Ti6Al4V by selective electron beam melting. Mater Charact 2013; vol.84: pp.153-68. doi:10.1016/j.matchar.2013.07.012.

[39] Edwards P, Ramulu M. Fatigue performance evaluation of selective laser melted Ti-6Al-4V. Mater Sci Eng A 2014; vol.598: pp.327-37. doi:10.1016/j.msea.2014.01.041.

[40] Barba D, Alabort C, Tang YT, Viscasillas MJ, Reed RC, Alabort E. On the size and orientation effect in additive manufactured Ti-6Al-4V. Mater Des 2020; vol.186: article 108235. doi:10.1016/j.matdes.2019.108235.

[41] Simonelli M, Tse YY, Tuck C. Effect of the build orientation on the mechanical properties and fracture modes of SLM ti-6Al-4V. Mater Sci Eng A 2014; 
vol.616: pp.1-11. doi:10.1016/j.msea.2014.07.086.

[42] Chan KS. Characterization and analysis of surface notches on Ti-alloy plates fabricated by additive manufacturing techniques. Surf Topogr Metrol Prop 2015; vol.3: article 44006. doi:10.1088/2051-672X/3/4/044006.

[43] Greitemeier D, Dalle Donne C, Syassen F, Eufinger J, Melz T. Effect of surface roughness on fatigue performance of additive manufactured Ti-6Al-4V. Mater Sci Technol 2016; vol.32: pp.629-34. doi:10.1179/1743284715Y.0000000053.

[44] Nicoletto G, Konečná R, Frkán̆ M, Riva E. Surface roughness and directional fatigue behavior of as-built EBM and DMLS Ti6Al4V. Int J Fatigue 2018; vol.116: pp.140-8. doi:10.1016/j.ijfatigue.2018.06.011.

[45] Liu QC, Elambasseril J, Sun SJ, Leary M, Brandt M, Sharp PK. The Effect of Manufacturing Defects on the Fatigue Behaviour of Ti-6Al-4V Specimens Fabricated Using Selective Laser Melting. Adv Mater Res 2014; vol.891-892: pp.1519-24. doi:10.4028/www.scientific.net/AMR.891-892.1519.

[46] Yang J, Han J, Yu H, Yin J, Gao M, Wang Z, et al. Role of molten pool mode on formability, microstructure and mechanical properties of selective laser melted Ti-6Al-4V alloy. Mater Des 2016; vol.110: pp.558-70. doi:10.1016/j.matdes.2016.08.036.

[47] Bauza MB, Moylan SP, Panas RM, Burke SC, Martz E, Taylor JS, et al. Study of accuracy of parts produced using additive manufacturing Carl Zeiss Industrial Metrology truss. 2014 ASPE Spring Top Meet Dimens Accuracy Surf Finish Addit Manuf, Berkeley, CA, United States, 2014. LLNL-CONF-651802.

[48] Koester LW, Taheri H, Bigelow TA, Collins PC, Bond LJ. Nondestructive testing for metal parts fabricated using powder-based additive manufacturing. Mater Eval 2018; vol.76: pp.514-24.

[49] de Formanoir C, Michotte S, Rigo O, Germain L, Godet S. Electron beam melted Ti-6Al-4V: Microstructure, texture and mechanical behavior of the asbuilt and heat-treated material. Mater Sci Eng A 2016; vol.652: pp.105-19. doi:10.1016/j.msea.2015.11.052.

[50] Black J, Kohser R. Degarmo's Materials and Processes in Manufacturing. 11th ed. Wiley 2012; pp.1040-1045.

[51] ImageJ, https://imagej.net (accessed August 20, 2020).

[52] Eriksson R. Thermal Barrier Coatings: Durability Assessment and Life Prediction. Dissertation No. 1527, Linköping University; 2013.

[53] Joint publication of Flugzeugwerke Emmen, Switzerland; Laboratorium für Betriebsfestigkeit (LBF), Germany; National Aerospace Laboratory (NLR), Netherlands; and Industrie-Anlagen-Betriebsgesellschaft mbH (IABG) G. FALSTAFF: Description of a fighter aircraft loading standard for fatigue evaluation. 1976.

[54] CEAT Report M7681900, Centre d'Essais Aeronautique de Toulouse, Toulouse. 1980. 
[55] Torstenfelt B. Trinitas Project www.solid.iei.liu.se/Offered_services/Trinitas (accessed April 16, 2021).

[56] Hellen TK. On the method of virtual crack extensions. Int J Numer Methods Eng 1975; vol.9: pp.187-207. doi:10.1002/nme.1620090114.

[57] Saab AB 2020. www.saab.com (accessed May 31, 2021).

[58] Oshida Y, Daly J. Fatigue Damage Evaluation of Shot Peened High Strength Aluminium alloy; Surface Engineering, Springer 1990; pp.404-16. doi:10.1007/978-94-009-0773-7.

[59] Bagehorn S, Wehr J, Maier HJ. Application of mechanical surface finishing processes for roughness reduction and fatigue improvement of additively manufactured Ti-6Al-4V parts. Int J Fatigue 2017; vol.102: pp.135-42. doi:10.1016/j.ijfatigue.2017.05.008.

[60] Denti L, Bassoli E, Gatto A, Santecchia E, Mengucci P. Fatigue life and microstructure of additive manufactured Ti6Al4V after different finishing processes. Mater Sci Eng A 2019; vol.755: pp.1-9. doi:10.1016/j.msea.2019.03.119.

[61] Wycisk E, Emmelmann C, Siddique S, Walther F. High Cycle Fatigue (HCF) Performance of Ti-6Al-4V Alloy Processed by Selective Laser Melting. Adv Mater Res 2013; vol.816-817: pp.134-9. doi:10.4028/www.scientific.net/AMR.816-817.134.

[62] Persenot T, Buffiere JY, Maire E, Dendievel R, Martin G. Fatigue properties of EBM as-built and chemically etched thin parts. Procedia Struct Integr 2017; vol.7: pp.158-65. doi:10.1016/j.prostr.2017.11.073.

[63] Theodore N. High Cycle Fatigue: A Mechanics of Materials Perspective. 1st ed. Elsevier Ltd; 2006: pp. 216-21.

[64] Nicoletto G, Konečna R, Frkan M, Riva E. Influence of layer-wise fabrication and surface orientation on the notch fatigue behavior of as-built additively manufactured Ti6A14V. Int J Fatigue 2020; vol.134; article 105483. doi:10.1016/j.ijfatigue.2020.105483.

[65] Paris P, Gomez M, Anderson W. A Rational Analytic Theory of Fatigue. Trend Eng 1961; vol.13: pp.9-14.

[66] Paris P, Erdogan F. A critical analysis of crack propagation laws. J Fluids Eng Trans ASME 1963; vol.85: pp.528-33. doi:10.1115/1.3656900.

[67] Leuders S, Thöne M, Riemer A, Niendorf T, Tröster T, Richard H a., et al. On the mechanical behaviour of titanium alloy TiAl6V4 manufactured by selective laser melting: Fatigue resistance and crack growth performance. Int $\mathrm{J}$ Fatigue 2013; vol.48: pp.300-7. doi:10.1016/j.ijfatigue.2012.11.011.

[68] Tarik Hasib M, Ostergaard HE, Li X, Kruzic JJ. Fatigue crack growth behavior of laser powder bed fusion additive manufactured Ti-6Al-4V: Roles of post heat treatment and build orientation. Int J Fatigue 2021; vol.142: article 105955. doi:10.1016/j.ijfatigue.2020.105955. 
[69] Syed AK, Ahmad B, Guo H, Machry T, Eatock D, Meyer J, et al. An experimental study of residual stress and direction-dependence of fatigue crack growth behaviour in as-built and stress-relieved selective-laser-melted Ti6Al4V. Mater Sci Eng A 2019; vol.755: pp.246-57. doi:10.1016/j.msea.2019.04.023.

[70] Cain V, Thijs L, Van Humbeeck J, Van Hooreweder B, Knutsen R. Crack propagation and fracture toughness of Ti6Al4V alloy produced by selective laser melting. Addit Manuf 2015; vol.5: pp.68-76. doi:10.1016/j.addma.2014.12.006.

[71] Forth S. NASA Johnson Space Center, The Purpose of Generating Fatigue Crack Growth Threshold Data. ASTM Comm. Meet., Atlanta, USA: 2006.

[72] Boyce BL, Ritchie RO. Effect of load ratio and maximum stress intensity on the fatigue threshold in Ti-6Al-4V. Eng Fract Mech 2001; vol.68: pp.129-47.

[73] Jiao ZH, Xu RD, Yu HC, Wu XR. Evaluation on Tensile and Fatigue Crack Growth Performances of Ti6A14V Alloy Produced by Selective Laser Melting. Procedia Struct Integr 2017; vol.7: pp.124-32. doi:10.1016/j.prostr.2017.11.069.

[74] Marsh G, Wignall C, Thies PR, Barltrop N, Incecik A, Venugopal V, et al. Review and application of rainflow residue processing techniques for accurate fatigue damage estimation. Int $\mathrm{J}$ Fatigue 2016; vol.82: pp.757-65. doi:10.1016/j.ijfatigue.2015.10.007.

[75] Pommier S. Cyclic plasticity and variable amplitude fatigue. Int J Fatigue 2003; vol.25: pp.983-97. doi:10.1016/S0142-1123(03)00137-3.

[76] Sarkar S, Kumar CS, Nath AK. Investigation on the mode of failures and fatigue life of laser-based powder bed fusion produced stainless steel parts under variable amplitude loading conditions. Addit Manuf 2019; vol.25: pp.71-83. doi:10.1016/j.addma.2018.10.044. 


\section{Part II: Papers Included}




\section{Papers}

The papers associated with this thesis have been removed for copyright reasons. For more details about these see:

http://urn.kb.se/resolve?urn=urn:nbn:se:liu:diva-178726 


\section{FACULTY OF SCIENCE AND ENGINEERING}

Linköping Studies in Science and Technology, Dissertation No. 2143, 2021 Department of Management and Engineering

Linköping University

SE-581 83 Linköping, Sweden

\section{www.liu.se}

Additive manufacturing [3D-printing] provides the engineer with a great freedom of design which means that parts with very complex geometries can be manufactured and light weight designs, multifunctional applications and improved part performance can be achieved through innovative design solutions.

This has attracted a lot of interest from the aerospace industry but there are still some challenges to solve, in which the fatigue related areas are addressed in this thesis, before additive manufacturing can be fully introduced to critical aerospace applications.

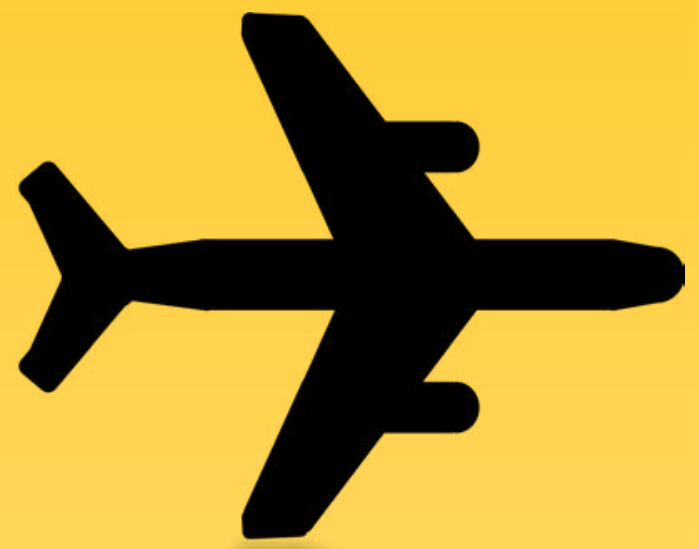

